Supporting Information

\title{
Template-directed Nonenzymatic Primer Extension Using 2- methylimidazole-activated Morpholino Derivatives of Guanosine and Cytidine
}

Weicheng Zhang, Ayan Pal, Alonso Ricardo, and Jack W. Szostak*

Howard Hughes Medical Institute, Department of Molecular Biology, and Center for Computational and Integrative Biology, Massachusetts General Hospital, Boston, Massachusetts 02114, United States

*To whom correspondence should be addressed:

CCIB 7215, Simches Research Center

185 Cambridge Street

Massachusetts General Hospital

Boston, Massachusetts 02114

E-mail: szostak@molbio.mgh.harvard.edu 


\section{Contents}

1. General information $\quad$ S3

2. Synthesis of activated MoNA monomers and morpholino nucleosides S3

3. Preparation of solid supports loaded with morpholino nucleosides $\quad$ S8

4. Protocol for primer extension reaction S9

5. Supporting table $\quad \mathrm{S} 11$

6. Supporting figures $\quad \mathrm{S} 12$

7. X-ray crystallography $\quad$ S23

$\begin{array}{ll}\text { 8. NMR spectra } & \text { S28 }\end{array}$

9. References $\quad$ S34 


\section{General information}

All solvents and reagents were reagent grade, purchased commercially, and used without further purification unless specified. Oligonucleotides used as primers or templates were synthesized on an Expedite nucleic acid synthesizer (Applied BioSystems) or purchased from IDT (Coralville, IA) unless otherwise indicated. All chemicals were purchased from Sigma-Aldrich (St. Louis, MO) unless otherwise indicated. All nucleoside-5'-monophosphates were purchased as the free acids from Santa Cruz Biotechnology (Dallas, TX). Reverse phase flash chromatography was performed using a RediSep Rf Gold C18Aq $50 \mathrm{~g}$ column purchased from Teledyne Isco (Lincoln, NE). All Nuclear Magnetic Resonance (NMR) real-time studies and NMR spectra were recorded on a Varian Oxford AS-400 NMR spectrometer. ${ }^{1} \mathrm{H},{ }^{13} \mathrm{C}$ and ${ }^{31} \mathrm{P}$ NMR spectra were acquired at $400 \mathrm{MHz}, 100 \mathrm{MHz}$ and $161.8 \mathrm{MHz}$, respectively. Chemical shifts are reported in parts per million. Electrospray mass spectra were recorded on a Bruker Daltonics Esquire 6000 ESI-MS (Billerica, MA). LC-MS studies of oligonucleotides were carried out on Agilent Q-TOF LC/MS system (Agilent Technologies, Santa Clara, CA).

\section{Synthesis of activated MoNA monomers and morpholino nucleosides}

\section{5'-phosphor-2-methylimidazolide of morpholino guanosine (2-MeImpmG)}

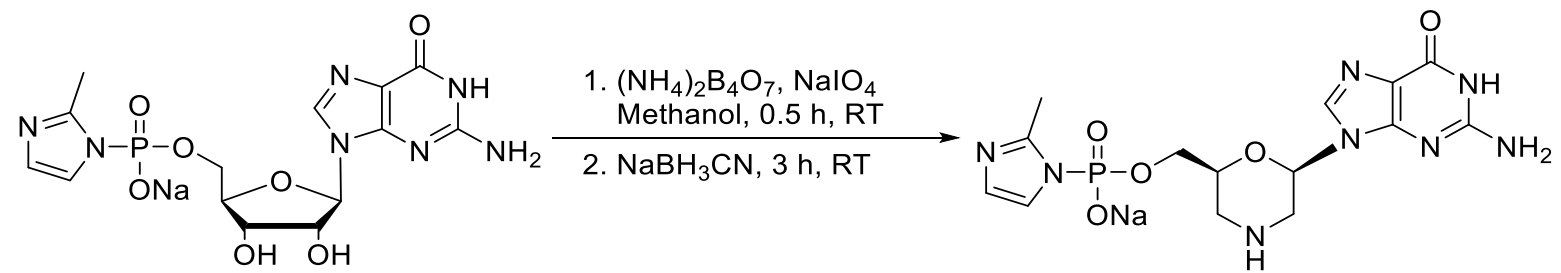

2-MeImpG (100 mg, $0.223 \mathrm{mmol}$ ), ammonium biborate (176 mg, $0.668 \mathrm{mmol}, 3.0$ equiv) and sodium periodate (143 mg, $0.668 \mathrm{mmol}, 3.0$ equiv) were stirred in anhydrous methanol (5 mL) in an oven-dried round bottom flask at room temperature under an inert atmosphere. After 30 min, sodium cyanoborohydride (140 mg, $2.23 \mathrm{mmol}, 10$ equiv) was added to the reaction mixture and stirring was continued at room temperature. After 3 hours, solvent was removed in a rotary evaporator under reduced pressure. The resultant solid residue was dissolved in $3 \mathrm{~mL}$ buffer (20 mM TEAB buffer, $\mathrm{pH} 10$ ) and purified by $\mathrm{C} 18$ column chromatography on a CombiFlash using 
gradient elution between (A) $20 \mathrm{mM}$ TEAB buffer, $\mathrm{pH} 10$ and (B) acetonitrile. The elution gradient was between $0 \%$ and $5 \%$ B over $6 \mathrm{CVs}$ with a flow rate of $40 \mathrm{~mL} / \mathrm{min} .0 .1 \mathrm{M} \mathrm{NaOH}$ was added drop wise to fractions containing product to adjust the $\mathrm{pH}$ to 10 . The resulting solution was then lyophilized at $-15{ }^{\circ} \mathrm{C}$ to afford 2-MeImpmG (58 mg, $0.134 \mathrm{mmol}, 60 \%$ yield) as a white fluffy solid. ${ }^{1} \mathrm{H}$ NMR $\left(400 \mathrm{MHz}, \mathrm{D}_{2} \mathrm{O}\right) \delta 7.78(\mathrm{~s}, 1 \mathrm{H}), 7.11(\mathrm{~m}, 1 \mathrm{H}), 6.68(\mathrm{~m}, 1 \mathrm{H})$, $5.52(\mathrm{dd}, \mathrm{J}=8.2,4.7 \mathrm{~Hz}, 1 \mathrm{H}), 4.01-3.79(\mathrm{~m}, 3 \mathrm{H}), 3.15-3.00(\mathrm{~m}, 2 \mathrm{H}), 2.85(\mathrm{dd}, \mathrm{J}=12.8,1.9 \mathrm{~Hz}$, $1 \mathrm{H}), 2.57(\mathrm{dd}, \mathrm{J}=12.9,11.3 \mathrm{~Hz}, 1 \mathrm{H}), 2.32(\mathrm{~s}, 3 \mathrm{H}) ;{ }^{31} \mathrm{P}$ NMR $\left(161.8 \mathrm{MHz}, 15 \% \mathrm{D}_{2} \mathrm{O}\right) \delta-11.3$; HRMS (Q-TOF) m/z: [M-H] ${ }^{-}$calculated for $\mathrm{C}_{14} \mathrm{H}_{19} \mathrm{~N}_{8} \mathrm{O}_{5} \mathrm{P}: 409.1143$; Found: 409.1238

\section{5'-phosphor-2-methylimidazolide of morpholino cytidine (2-MeImpmC)}

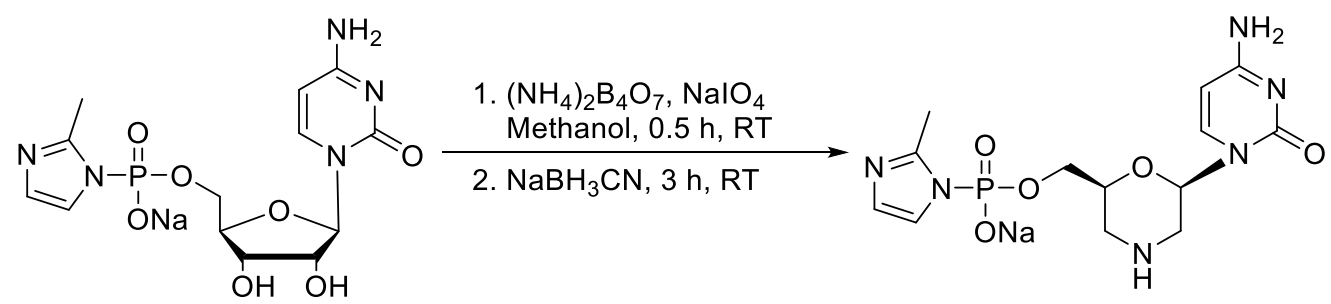

2-MeImpC (100 mg, $0.244 \mathrm{mmol})$, ammonium biborate (193 mg, $0.733 \mathrm{mmol}, 3.0$ equiv) and sodium periodate (157 mg, $0.733 \mathrm{mmol}, 3.0$ equiv) were stirred in anhydrous methanol $(5 \mathrm{~mL})$ in an oven-dried round bottom flask at room temperature under an inert atmosphere. After 30 min, sodium cyanoborohydride (154 mg, $2.44 \mathrm{mmol}, 10$ equiv) was added to the reaction mixture and stirring was continued at room temperature. After 3 hours, the solvent was removed in a rotary evaporator under reduced pressure. The resultant solid residue was dissolved in $3 \mathrm{~mL}$ buffer ( 20 mM TEAB buffer, $\mathrm{pH}$ 10) and purified by $\mathrm{C} 18$ column chromatography on a CombiFlash using gradient elution between (A) $20 \mathrm{mM}$ TEAB buffer, $\mathrm{pH} 10$ and (B) acetonitrile. The elution gradient was between $0 \%$ and $5 \% \mathrm{~B}$ over $6 \mathrm{CVs}$ with a flow rate of $40 \mathrm{~mL} / \mathrm{min}$. $0.1 \mathrm{M} \mathrm{NaOH}$ was added drop wise to fractions containing product to adjust the $\mathrm{pH}$ to 10 . The resulting solution was then lyophilized at $-15{ }^{\circ} \mathrm{C}$ to afford 2-MeImpmC ( $49 \mathrm{mg}, 0.125 \mathrm{mmol}, 51 \%$ yield) as a white solid. ${ }^{1} \mathrm{H}$ NMR (400 MHz, $\left.\mathrm{D}_{2} \mathrm{O}\right) \delta 7.58(\mathrm{~d}, \mathrm{~J}=7.4 \mathrm{~Hz}, 1 \mathrm{H}), 7.17(\mathrm{~m}, 1 \mathrm{H}), 6.79(\mathrm{~m}, 1 \mathrm{H}), 6.03(\mathrm{~d}$, $\mathrm{J}=7.5 \mathrm{~Hz}, 1 \mathrm{H}), 5.58(\mathrm{dd}, \mathrm{J}=10.2,2.8 \mathrm{~Hz}, 1 \mathrm{H}), 3.98-3.82(\mathrm{~m}, 3 \mathrm{H}), 2.97(\mathrm{dd}, \mathrm{J}=13.0,2.3 \mathrm{~Hz}$, 1H), $2.80(\mathrm{dd}, \mathrm{J}=13.2,2.3 \mathrm{~Hz}, 1 \mathrm{H}), 2.57(\mathrm{dd}, \mathrm{J}=12.5,10.0 \mathrm{~Hz}, 1 \mathrm{H}), 2.49(\mathrm{dd}, \mathrm{J}=13.1,10.6$ $\mathrm{Hz}, 1 \mathrm{H}), 2.41$ (s, 3H); ${ }^{31} \mathrm{P}$ NMR (161.8 MHz, 15\% D $\left.2 \mathrm{O}\right) \delta$-10.8; HRMS (Q-TOF) m/z: [M-H] ${ }^{-}$ calculated for $\mathrm{C}_{13} \mathrm{H}_{19} \mathrm{~N}_{6} \mathrm{O}_{5} \mathrm{P}: 369.1082$; Found: 369.1191 


\section{5'-O-DMTr-morpholino guanosine}

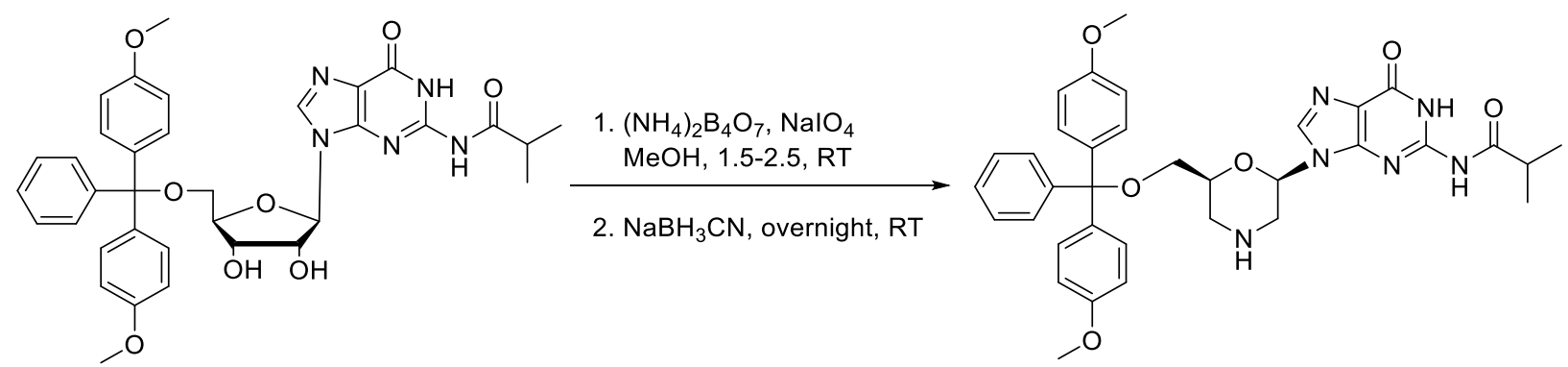

5'-O-DMTr-G ${ }^{\mathrm{iBu}}(5.00 \mathrm{~g}, 7.63 \mathrm{mmol})$ was dissolved in methanol (100 mL). Ammonium biborate tetrahydrate $(2.41 \mathrm{~g}, 9.15 \mathrm{mmol}, 1.2$ equiv) and sodium periodate (1.96 g, $9.15 \mathrm{mmol}, 1.2 \mathrm{equiv})$ were added at room temperature with stirring. The reaction mixture was allowed to stir for $2 \mathrm{~h}$. ESI-MS was used to monitor the progress of the reaction. After complete consumption of the starting material, the reaction mixture was centrifuged at $4000 \mathrm{rpm}$ for $15 \mathrm{~min}$ to remove excess reagents and byproducts. Sodium cyanoborohydride (958 mg, $15.3 \mathrm{mmol}, 2.0$ equiv) was added to the supernatant. After $30 \mathrm{~min}$, another equivalent of sodium cyanoborohydride (479 $\mathrm{mg}, 7.63$ mmol, 1.0 equiv) was added. The reaction mixture was allowed to stir for another $6 \mathrm{~h}$, at which point the intermediate product was completely reduced. The solvent was then removed by rotary evaporation under reduced pressure. The resulting residue was dissolved in ethyl acetate (200 $\mathrm{mL}$ ) and washed with brine three times. The solution was then dried over sodium sulfate and the solvent removed under reduced pressure. The crude product was purified by column chromatography (silica column, $0-10 \% \mathrm{MeOH}$ in DCM) to afford the desired product (4.12 $\mathrm{g}$, $6.45 \mathrm{mmol}, 85 \%$ yield) as a white solid. ${ }^{1} \mathrm{H}$ NMR (400 MHz, CD $\left.{ }_{3} \mathrm{OD}\right) \delta 8.06(\mathrm{~s}, 1 \mathrm{H}), 7.37$ (d, J = 7.5 Hz, 2H), 7.27-7.10 (m, 7H), $6.75(\mathrm{~d}, \mathrm{~J}=8.7 \mathrm{~Hz}, 4 \mathrm{H}), 5.73(\mathrm{dd}, \mathrm{J}=9.0,3.6 \mathrm{~Hz}, 1 \mathrm{H}), 4.00$ (m, 1H), $3.69(\mathrm{~s}, 6 \mathrm{H}), 3.22-3.12(\mathrm{~m}, 3 \mathrm{H}), 3.03(\mathrm{dd}, \mathrm{J}=9.9,5.6 \mathrm{~Hz}, 1 \mathrm{H}), 2.97(\mathrm{dd}, \mathrm{J}=12.6,2.0 \mathrm{~Hz}$, 1H), $2.67(\mathrm{~m}, 1 \mathrm{H}), 2.64(\mathrm{~m}, 1 \mathrm{H}), 1.18(\mathrm{~d}, \mathrm{~J}=6.7 \mathrm{~Hz}, 6 \mathrm{H}) ;{ }^{13} \mathrm{C} \mathrm{NMR}\left(100 \mathrm{MHz}, \mathrm{CD}_{3} \mathrm{OD}\right) \delta$ $181.7,160.0,157.4,150.1,149.8,146.3,139.1,137.1,137.0,131.2,129.2$, 128.7, 127.8, 121.0, 114.0, 87.4, 81.5, 78.3, 65.6, 55.7, 47.6, 36.9, 19.3; ESI-MS m/z: [M-H] ${ }^{-}$calculated for $\mathrm{C}_{35} \mathrm{H}_{38} \mathrm{~N}_{6} \mathrm{O}_{6}$ : 637.3; Found: 637.4 


\section{5'-O-DMTr-morpholino cytidine}

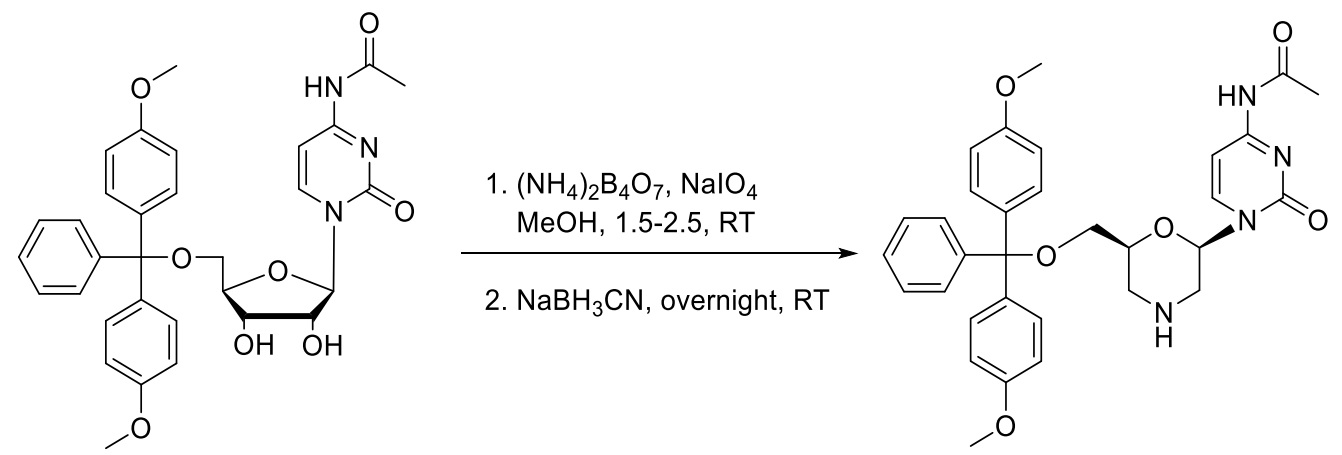

5'-O-DMTr-C ${ }^{\text {Ac }}(5.00 \mathrm{~g}, 8.51 \mathrm{mmol})$ was dissolved in methanol (100 mL). Ammonium biborate tetrahydrate ( $2.69 \mathrm{~g}, 10.2 \mathrm{mmol}, 1.2$ equiv) and sodium periodate ( $2.18 \mathrm{~g}, 10.2 \mathrm{mmol}, 1.2 \mathrm{equiv})$ were added at room temperature with stirring. The reaction mixture was allowed to stir for $2 \mathrm{~h}$. ESI-MS was used to monitor the progress of the reaction. After complete consumption of the starting material, the reaction mixture was centrifuged at $4000 \mathrm{rpm}$ for $15 \mathrm{~min}$ to remove excess reagents and byproducts. Sodium cyanoborohydride ( $1.07 \mathrm{~g}, 17.0 \mathrm{mmol}, 2.0$ equiv) was added to the supernatant. After $30 \mathrm{~min}$, another equivalent of sodium cyanoborohydride $(535 \mathrm{mg}, 8.51$ mmol, 1.0 equiv) was added. The reaction mixture was allowed to stir for another $6 \mathrm{~h}$, at which point the intermediate product was completely reduced. The solvent was then removed by rotary evaporation under reduced pressure. The resulting residue was dissolved in ethyl acetate (200 $\mathrm{mL}$ ) and washed with brine three times. The solution was then dried over sodium sulfate and the solvent removed under reduced pressure. The crude product was purified by column chromatography (silica column, $0-10 \% \mathrm{MeOH}$ in DCM) to afford the desired product (4.34 g, $7.61 \mathrm{mmol}, 89 \%$ yield) as a white solid. ${ }^{1} \mathrm{H} \mathrm{NMR}\left(400 \mathrm{MHz}, \mathrm{CD}_{3} \mathrm{OD}\right) \delta 7.94(\mathrm{~d}, \mathrm{~J}=7.4 \mathrm{~Hz}, 1 \mathrm{H})$, 7.43-7.37 (m, 3H), 7.29-7.09 (m, 7H), 6.76 (d, J = 9.0 Hz, 4H), 5.77 (dd, J = 9.8, 2.5 Hz, 1H), $3.97(\mathrm{~m}, 1 \mathrm{H}), 3.67(\mathrm{~s}, 6 \mathrm{H}), 3.23(\mathrm{dd}, \mathrm{J}=9.8,5.3 \mathrm{~Hz}, 1 \mathrm{H}), 3.16(\mathrm{~d}, \mathrm{~J}=10.8 \mathrm{~Hz}, 1 \mathrm{H}), 3.07$ (dd, J = 10.3, 5.0 Hz, 1H), 2.90 (d, J = 11.3 Hz, 1H), 2.56 (dd, J = 12.8, $11.3 \mathrm{~Hz}, 1 \mathrm{H}), 2.47$ (dd, J = 12.6, $10.3 \mathrm{~Hz}, 1 \mathrm{H}), 2.14$ (s, 3H); ${ }^{13} \mathrm{C}$ NMR (100 MHz, CD $\left.3 \mathrm{OD}\right) \delta 172.9,164.2,160.0,157.1,146.2$, 145.9, 137.1, 137.0, 131.2, 129.2, 128.8, 127.8, 114.1, 98.2, 87.4, 83.2, 78.8, 65.6, 55.7, 47.4, 24.6; ESI-MS m/z: [M-H] $]^{-}$calculated for $\mathrm{C}_{32} \mathrm{H}_{34} \mathrm{~N}_{4} \mathrm{O}_{6}$ : 569.2; Found: 569.2 


\section{Morpholino guanosine}

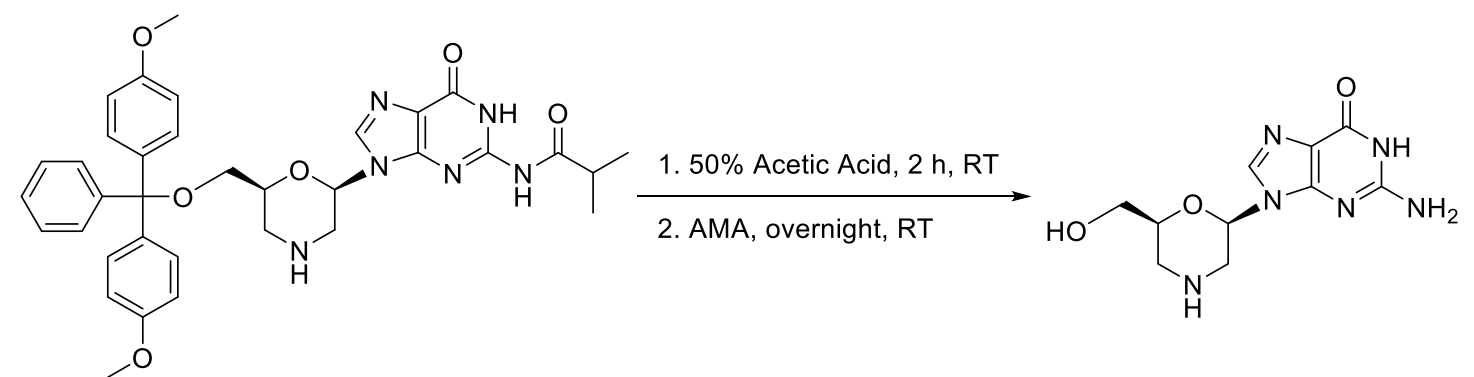

5'-O-DMTr-morpholino-G $\mathrm{G}^{\mathrm{iBu}}\left(500 \mathrm{mg}, 0.783 \mathrm{mmol}\right.$ ) was mixed with $50 \%$ acetic acid in $\mathrm{H}_{2} \mathrm{O}$ $(100 \mathrm{~mL})$ at room temperature. The reaction mixture was stirred at $\mathrm{rt}$ for $2 \mathrm{~h}$. ESI-MS was used to monitor the reaction progress. After complete consumption of the starting material, volatiles were removed in vacuo. Resulting residue was transferred to a pressure vessel in $\mathrm{H}_{2} \mathrm{O}(5 \mathrm{~mL})$. $28-30 \% \mathrm{NH}_{4} \mathrm{OH}$ in $\mathrm{H}_{2} \mathrm{O}(100 \mathrm{~mL}), 40 \%$ methylamine in $\mathrm{H}_{2} \mathrm{O}(100 \mathrm{~mL})$ was added. The mixture was stirred in the sealed flask for $16 \mathrm{~h}$. Volatiles were removed in vacuo, and the residue was purified by $\mathrm{C} 18$ column chromatography on a CombiFlash system using gradient elution between (A) $20 \mathrm{mM}$ TEAB buffer, $\mathrm{pH} 7.5$ and (B) acetonitrile. The elution gradient was between $0 \%$ and $10 \% \mathrm{~B}$ over $6 \mathrm{CVs}$ with a flow rate of $40 \mathrm{~mL} / \mathrm{min}$. Collected fractions were then lyophilized to afford the desired product (168 $\mathrm{mg}, 0.631 \mathrm{mmol}, 81 \%$ yield) as a white fluffy solid. ${ }^{1} \mathrm{H}$ NMR (400 MHz, D $2 \mathrm{O}) \delta 7.96(\mathrm{~s}, 1 \mathrm{H}), 5.65(\mathrm{t}, \mathrm{J}=6.2 \mathrm{~Hz}, 1 \mathrm{H}), 3.99(\mathrm{~m}, 1 \mathrm{H}), 3.68(\mathrm{dd}, \mathrm{J}=12.1,2.7 \mathrm{~Hz}$, $1 \mathrm{H}), 3.62(\mathrm{dd}, \mathrm{J}=12.1,5.4 \mathrm{~Hz}, 1 \mathrm{H}), 3.17(\mathrm{~m}, 2 \mathrm{H}), 2.93(\mathrm{~d}, \mathrm{~J}=12.5 \mathrm{~Hz}, 1 \mathrm{H}), 2.66(\mathrm{~m}, 1 \mathrm{H}) ;{ }^{13} \mathrm{C}$ NMR (100 MHz, $\left.\mathrm{D}_{2} \mathrm{O}\right) \delta$ 160.3, 155.2, 151.8, 138.0, 116.8, 80.4, 78.9, 62.8, 47.7, 45.0; ESI-MS m/z: [M-H] $]^{-}$calculated for $\mathrm{C}_{10} \mathrm{H}_{14} \mathrm{~N}_{6} \mathrm{O}_{3}$ : 265.1; Found: 265.0; Cambridge Crystallographic Data Centre deposition number 1916567.

\section{Morpholino cytidine}

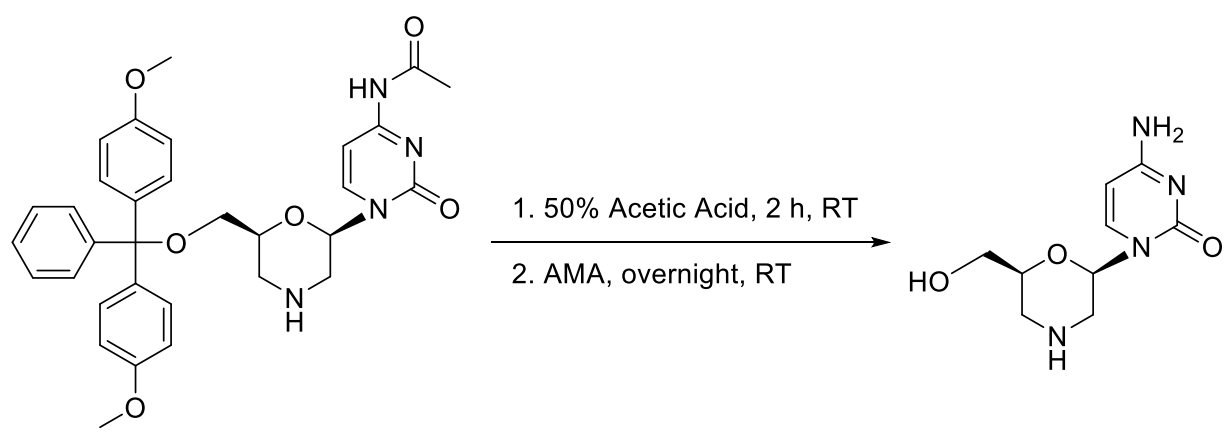


5'-O-DMTr-morpholino $\mathrm{C}^{\mathrm{Ac}}$ (500 mg, $0.876 \mathrm{mmol}$ ) was mixed with $50 \%$ acetic acid in $\mathrm{H}_{2} \mathrm{O}$ $(100 \mathrm{~mL})$ at room temperature. The reaction mixture was stirred at $\mathrm{rt}$ for $2 \mathrm{~h}$. ESI-MS was used to monitor the reaction progress. After complete consumption of the starting material, volatiles were removed in vacuo. The resulting residue was transferred to a pressure vessel in $\mathrm{H}_{2} \mathrm{O}$ (5 $\mathrm{mL})$. $28-30 \% \mathrm{NH}_{4} \mathrm{OH}$ in $\mathrm{H}_{2} \mathrm{O}(100 \mathrm{~mL})$ and $40 \%$ methylamine in $\mathrm{H}_{2} \mathrm{O}(100 \mathrm{~mL})$ was added. The mixture was stirred in the sealed flask for $16 \mathrm{~h}$. Volatiles were removed in vacuo, and the residue was purified by $\mathrm{C} 18$ column chromatography on a CombiFlash system using gradient elution between (A) $20 \mathrm{mM}$ TEAB buffer, $\mathrm{pH} 7.5$ and (B) acetonitrile. The elution gradient was between $0 \%$ and $10 \% \mathrm{~B}$ over $6 \mathrm{CVs}$ with a flow rate of $40 \mathrm{~mL} / \mathrm{min}$. Collected fractions were then lyophilized to afford the desired product ( $179 \mathrm{mg}, 0.791 \mathrm{mmol}, 90 \%$ yield) as a white solid. ${ }^{1} \mathrm{H}$ NMR (400 MHz, $\left.\mathrm{D}_{2} \mathrm{O}\right) \delta 7.76(\mathrm{~d}, \mathrm{~J}=7.5 \mathrm{~Hz}, 1 \mathrm{H}), 6.02(\mathrm{~d}, \mathrm{~J}=7.5 \mathrm{~Hz}, 1 \mathrm{H}), 5.72(\mathrm{dd}, \mathrm{J}=10.2$, $2.7 \mathrm{~Hz}, 1 \mathrm{H}), 3.91(\mathrm{~m}, 1 \mathrm{H}), 3.67(\mathrm{dd}, \mathrm{J}=12.1,3.9 \mathrm{~Hz}, 1 \mathrm{H}), 3.62(\mathrm{dd}, \mathrm{J}=12.1,5.9 \mathrm{~Hz}, 1 \mathrm{H}), 3.02$ (dd, J = 13.0, $2.5 \mathrm{~Hz}, 1 \mathrm{H}), 2.87$ (dd, J = 12.9, $2.4 \mathrm{~Hz}, 1 \mathrm{H}), 2.66(\mathrm{dd}, \mathrm{J}=13.1,10.3 \mathrm{~Hz}, 1 \mathrm{H}), 2.57$ $(\mathrm{dd}, \mathrm{J}=13.4,11.4 \mathrm{~Hz}, 1 \mathrm{H}) ;{ }^{13} \mathrm{C}$ NMR $\left(100 \mathrm{MHz}, \mathrm{D}_{2} \mathrm{O}\right) \delta 166.9,157.9,142.6,97.1,81.9,79.1$, 62.8, 47.9, 44.9; ESI-MS m/z: [M-H] ${ }^{-}$calculated for $\mathrm{C}_{9} \mathrm{H}_{14} \mathrm{~N}_{4} \mathrm{O}_{3}$ : 225.1; Found: 225.0; Cambridge Crystallographic Data Centre deposition number 1916568.

\section{Preparation of solid supports loaded with morpholino nucleosides}

Native long chain alkylamine controlled pore glass (LCAA-CPG) was coevaporated with toluene and dried under vacuum overnight. The dried CPG was mixed with DCM under an inert atmosphere. DIEA (12 equiv), and hexafluoroglutaric anhydride (10 equiv) were then added. The mixture was shaken at room temperature overnight. The CPG was then isolated by filtration and washed sequentially with $1 \%$ TEA in DMF, MeOH, and DCM. 5'-O-DMTr-morpholino-G ${ }^{\mathrm{iBu}}$ (3 equiv) were then added. The resulting mixture was coevaporated with toluene under reduced pressure and dried under vacuum. $\mathrm{DMF}, \mathrm{PPh}_{3}$ (5 equiv), and DIEA (12 equiv) were added to the residue. A solution of iodine (5 equiv) in DMF was then added dropwise with stirring. After 16 $\mathrm{h}$, the derivatized CPG was isolated by filtration, washed sequentially with 1\% TEA in DMF, $\mathrm{MeOH}$ and DCM, and dried under vacuum. 


\section{Protocol for primer extension reaction}

\section{General protocol for PAGE analysis of primer extension reactions}

Representative reaction protocol: $6.0 \mu \mathrm{L}$ of 1.0 M HEPES pH 7.5 buffer, $3.0 \mu \mathrm{L}$ nuclease-free water, $3.0 \mu \mathrm{L} 10 \mu \mathrm{M}$ primer and $3.0 \mu \mathrm{L} 50 \mu \mathrm{M}$ template were combined in a thin-walled PCR micro-tube. $15 \mu \mathrm{L}$ of $5 \mathrm{mM}$ 2-MeImpmG was added to the lid of the micro-tube cap. The reaction was initiated when the activated nucleotides were spun down into the buffered primer/template solution. $2.0 \mu \mathrm{L}$ aliquots were removed at desired time points, and were immediately quenched by addition to $38 \mu \mathrm{L}$ quenching buffer ( $8.0 \mathrm{M}$ urea in $1 \mathrm{xTBE})$. The sample was incubated at $90{ }^{\circ} \mathrm{C}$ for 1 minute before the primer extension products were separated by $20 \%$ (19:1) denaturing PAGE. The gel was scanned with a Typhoon 9410 Variable Mode Imager. The bands were quantified using the ImageQuant TL software package.

\section{General protocol for LC-MS analysis of primer extension reactions}

A primer extension reaction mixture $(30 \mu \mathrm{L})$ containing $7 \mu \mathrm{M}$ primer, $12.5 \mu \mathrm{M}$ template, 200 $\mathrm{mM}$ HEPES ( $\mathrm{pH} 7.5$ ), and $3 \mathrm{mM}$ activated monomers was allowed to react for 1 day. Primer and extended products were separated from monomers by Sephadex G-25 size exclusion column chromatography (GE Healthcare, Buckinghamshire, UK). The solution was desalted by ion pairing reverse phase (IP-RP) purification on a C18 ZipTip pipette tip (Millipore, Billerica, MA). The tip was wetted with acetonitrile and equilibrated with 2 M TEAA prior to sample binding. Extensive washing with $10 \mathrm{mM}$ TEAA was followed by elution in $50 \%$ acetonitrile. The eluate was dried under vacuum, followed by resuspension in LC-MS grade water. The eluted sample was analyzed on an Agilent 1200 high-performance liquid chromatography system coupled to an Agilent 6230 time-of-flight mass spectrometer. The LC-MS setup contains solvent degasser, temperature controlled auto sampler, column oven, and diode array detector. The sample was separated by a $100 \mathrm{~mm}$ X $1 \mathrm{~mm}$ Xbridge C18 column with $3.5 \mu \mathrm{m}$ particle size (Waters, Milford, MA) using gradient elution between (A) aqueous $200 \mathrm{mM}$ 1,1,1,3,3,3-hexafluoro-2-propanol with $1.25 \mathrm{mM}$ triethylamine, $\mathrm{pH} 7.0$, and (B) methanol. The elution gradient was from $2.5 \%$ to $90 \% \mathrm{~B}$ over $40 \mathrm{~min}$ with a flow rate of $0.1 \mathrm{~mL} / \mathrm{min}$ at $60{ }^{\circ} \mathrm{C}$. Samples were analyzed in negative 
mode using the following instrument settings: mass range, $239 \mathrm{~m} / \mathrm{z}$ to $3200 \mathrm{~m} / \mathrm{z}$; scan rate, 1 spectrum/s; drying gas flow, $8 \mathrm{~L} / \mathrm{min}$; drying gas temperature, $325{ }^{\circ} \mathrm{C}$; nebulizer pressure, 30 psig; capillary voltage, -3500 V; fragmentor, $200 \mathrm{~V}$; and skimmer, $65 \mathrm{~V}$. Extracted ion chromatograms were produced with MassHunter Qualitative Analysis software from Agilent Technologies. 


\section{Supporting table}

Table S1: Sequences of oligonucleotides used in this study

$\begin{array}{cc}\text { Name } & \text { Sequence }\left(5^{\prime} \rightarrow 3^{\prime}\right) \\ \text { P1 } & \text { Cy5-GACUGACUGmG } \\ \text { P2 } & \text { Cy5-GACUGACUGG } \\ \text { P3 } & \text { Cy3-AGUGAGUAACGmC } \\ \text { P4 } & \text { Cy3-AGUGAGUAACGC }{ }^{\text {NH2 }} \\ \text { P5 } & \text { Cy5-GACUGACUGmGmGmG } \\ \text { T1 } & \text { AACCCCCCAGUCAGUC } \\ \text { T2 } & \text { AACCCCGCGUUACUCACU } \\ \text { T3 } & \text { AAGGGGCCAGUCAGUC } \\ \text { T4 } & \text { AAGGGGGCGUUACUCACU } \\ \text { T5 } & \text { AACCCGCCAGUCAGUC } \\ \text { T6 } & \text { AAGGGCCCAGUCAGUC } \\ \text { T7 } & \text { AACGGGCCAGUCAGUC } \\ \text { T8 } & \text { AAGCCCCAGUCAGUC } \\ \text { T9 } & \text { CCAAAACCAGUCAGUC } \\ \text { T10 } & \text { AACCCCCCCAGUCAGUC }\end{array}$

Cy5 is cyanine 5; $\mathrm{Cy} 3$ is cyanine $3 ; \mathrm{mG}$ is morpholino modified guanosine; $\mathrm{mC}$ is morpholino modified cytidine; $\mathrm{C}_{\mathrm{NH} 2}$ is 3'-amino-2',3'-dideoxycytidine. 


\section{Supporting figures}

a)

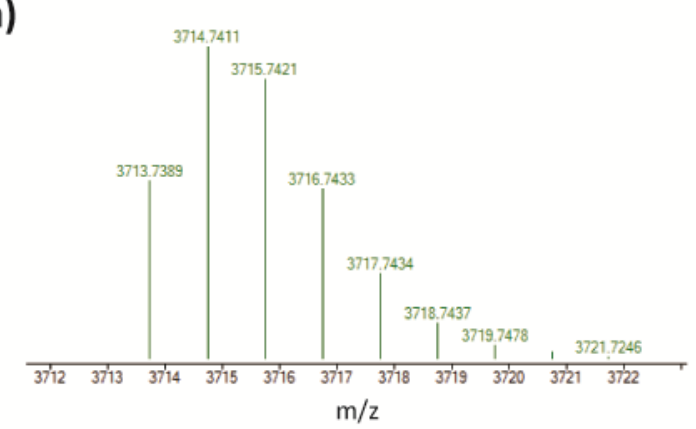

b)

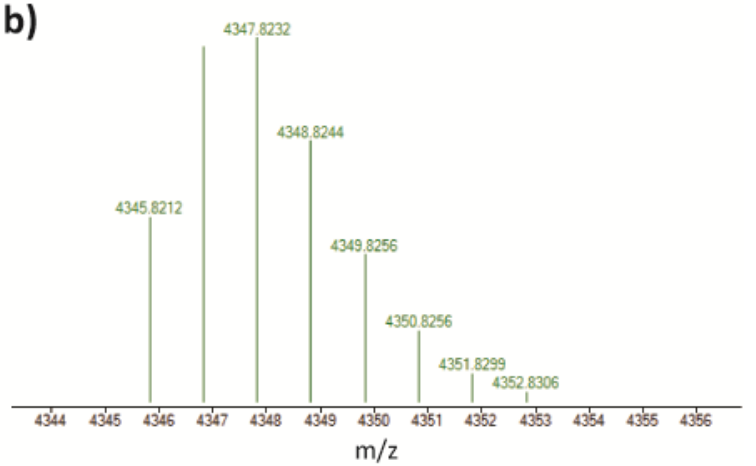

Figure S1. LC-MS analysis of the fluorescent dye-labeled chimeric RNA/MoNA oligonucleotides generated by solid phase synthesis. (a) 5'-Cy5 tagged 3'-morpholino G terminated RNA oligo (Cy5-GACUGACUGmG, P1). Chemical formula, $\mathrm{C}_{127} \mathrm{H}_{157} \mathrm{~N}_{43} \mathrm{O}_{70} \mathrm{P}_{10}$; calculated exact mass, $3713.7424 \mathrm{Da}$; measured accurate mass, $3713.7389 \mathrm{Da}$; error, $0.9 \mathrm{ppm}$. (b) 5'-Cy3 tagged 3'-morpholino $\mathrm{C}$ terminated RNA oligo (Cy3-AGUGAGUAACGmC, P3). Chemical formula, $\mathrm{C}_{145} \mathrm{H}_{179} \mathrm{~N}_{53} \mathrm{O}_{82} \mathrm{P}_{12}$; calculated exact mass, $4345.8317 \mathrm{Da}$; measured accurate mass, 4345.8212 Da; error, 2.4 ppm. 
a)

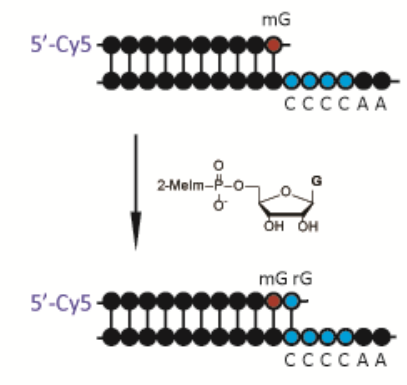

c)

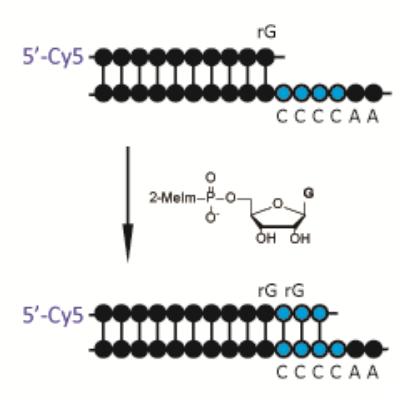

b)

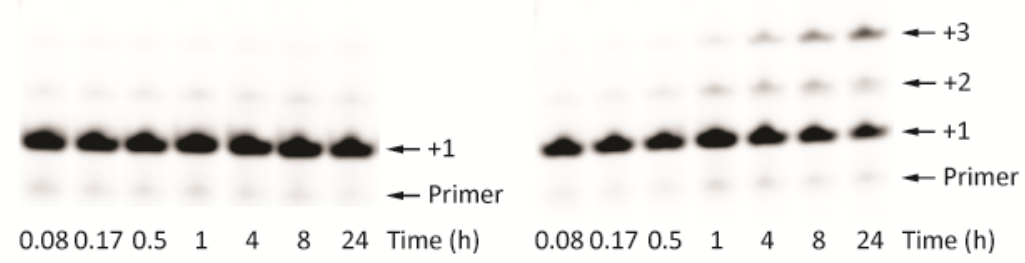

d)

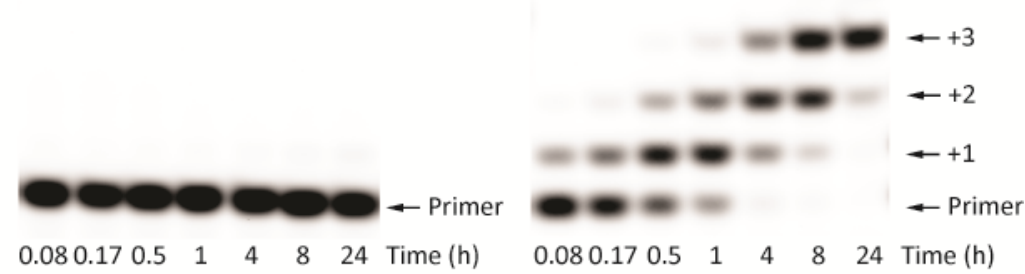

Figure S2. Comparison between chimeric RNA/MoNA oligonucleotide and regular RNA oligonucleotide in nonenzymatic primer extension reaction in the presence of activated RNA monomer (2-MeImpG). (a) Schematic representation of 3'-morpholino-modified primer P1 annealed to a $\mathrm{C}_{4}$ RNA template (T1) in presence of 2-MeImpG. (b) High resolution gel electrophoresis analysis of nonenzymatic primer extension reactions with 2-MeImpG on 3'morpholino terminated oligonucleotide. Primer-extension reactions contained $1 \mu \mathrm{M}$ P1, $5 \mu \mathrm{M}$ T1, $200 \mathrm{mM}$ HEPES pH 7.5, and $5 \mathrm{mM}$ 2-MeImpG. $100 \mathrm{mM} \mathrm{MgCl} 2$ was added to the reaction mixture for the time course on the right. (c) Schematic representation of RNA primer P2 annealed to a $\mathrm{C}_{4}$ RNA template (T1) in presence of 2-MeImpG. (d) High resolution gel electrophoresis analysis of nonenzymatic primer extension reactions with 2-MeImpG on RNA primer. Primer-extension reactions contained $1 \mu \mathrm{M}$ P2, $5 \mu \mathrm{M}$ T1, $200 \mathrm{mM}$ HEPES pH 7.5, and 5 mM 2-MeImpG. $100 \mathrm{mM} \mathrm{MgCl}_{2}$ was added to the reaction mixture for the time course on the right. 
a)

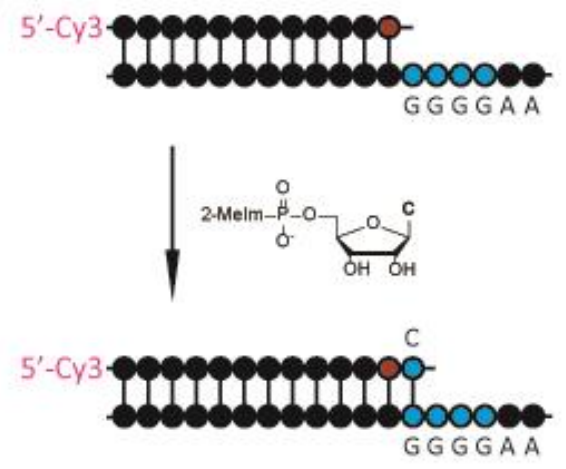

b)

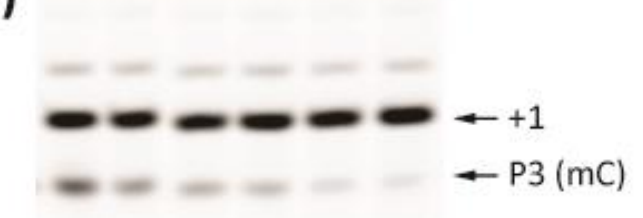

$1510 \quad 30 \quad 60 \quad 120$ Time(min)

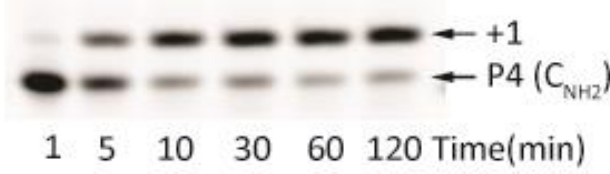

Figure S3. Nonenzymatic primer-extension reactions with 3'-terminal amine and 3'-morpholino modified primers. (a) Schematic representation of 3'-terminally modified primers $\mathbf{P 3}$ or $\mathbf{P 4}$ annealed to a $\mathrm{G}_{4} \mathrm{RNA}$ template (T4) in presence of 2-MeImpC. The monomers participate in primer extension reaction on the corresponding template region resulting in predominantly $\mathrm{N}+1$ product. (b) High-resolution PAGE analysis of the primer-extension products at different reaction time. Reaction conditions: $1 \mu \mathrm{M}$ primer P3, $5 \mu \mathrm{M} \mathrm{G}_{4}$ template T4, $200 \mathrm{mM}$ HEPES $\mathrm{pH}$ 7.5, 5 mM 2-MeImpG. (c) PAGE analysis of the primer-extension products when $\mathbf{P 4}$ was used. 
a)

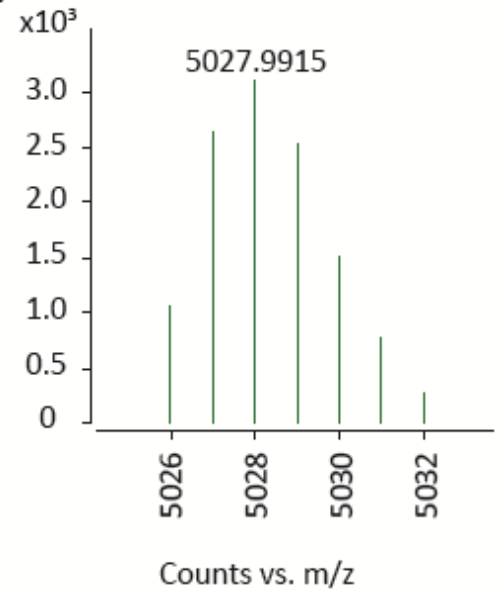

b)

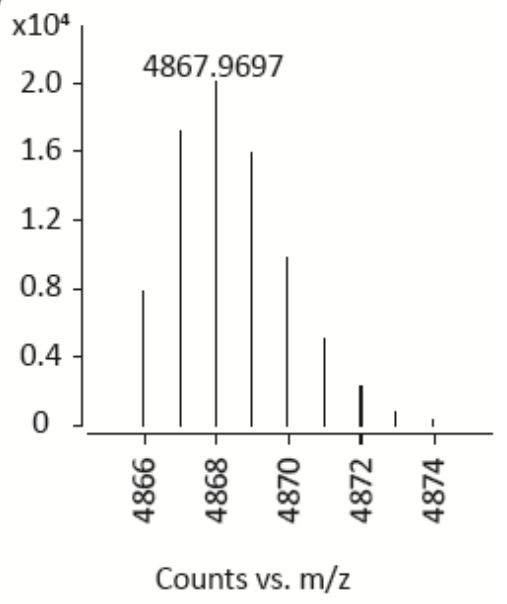

Figure S4. LC-MS analysis of the major primer extension products formed by template copying with activated MoNA monomers. (a) Deconvoluted mass of +4 product formed on the RNA $\mathrm{C}_{4}$ template T1 with 2-MeImpmG. Monoisotopic mass for the full-length primer $+4 \mathrm{G}$ product: calculated mass, 5026.0164 Da; observed mass, 5025.9896 Da; error, 5.3 ppm. Reaction conditions: $2.75 \mu \mathrm{M}$ primer P1, $10 \mu \mathrm{M}$ template T1, $200 \mathrm{mM}$ HEPES pH 7.5, $5 \mathrm{mM}$ 2MeImpmG. (b) Deconvoluted mass of +4 product formed on the RNA G $\mathrm{G}_{4}$ template $\mathbf{T 3}$ with 2MeImpmC. Monoisotopic mass for the full-length primer $+4 \mathrm{C}$ product: calculated mass, 4865.9918 Da; observed mass, 4865.9729 Da; error, 3.9 ppm. Reaction conditions: $2.75 \mu \mathrm{M}$ primer P1, $10 \mu \mathrm{M}$ template T3, $200 \mathrm{mM}$ HEPES pH 7.5, 5 mM 2-MeImpmC. 
a)

$$
\begin{aligned}
& \text { Cy5-GACUGACUGmG } \\
& \text { CUGACUGACCCCCCAA }
\end{aligned}
$$

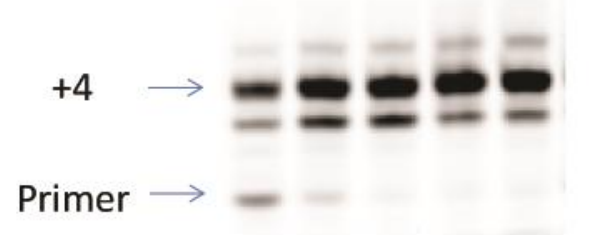

Time (min) $\quad 1 \quad 5 \quad 10 \quad 30 \quad 60$

b)

$$
\begin{aligned}
& \text { Cy5-GACUGACUGmG } \\
& \text { CUGACUGACCGGGGAA }
\end{aligned}
$$

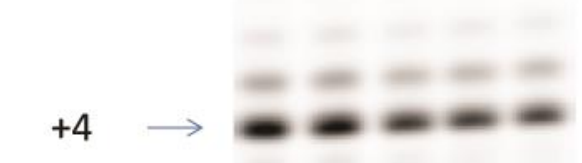

Primer $\longrightarrow$

Time (min) $115 \quad 10 \quad 30 \quad 60$
Cy5-GACUGACUGmG

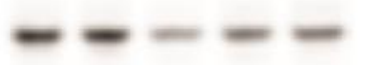

$\begin{array}{lllll}1 & 5 & 10 & 30 & 60\end{array}$

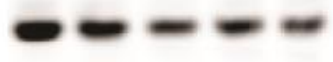

$\begin{array}{lllll}1 & 5 & 10 & 30 & 60\end{array}$

Cy5-GACUGACUGmG

CY5-GACUGACUGmG CUGACUGACCCCCCAA

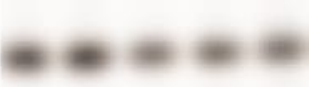

$151030 \quad 60$
CY5-GACUGACUGmG

CUGACUGACCAAAACC

Figure S5. Primer extension with activated morpholino-nucleotides is template dependent. (a) High resolution gel electrophoresis analysis of primer extension reaction with 2-MeImpmG. Primer-extension reactions contained $1 \mu \mathrm{M}$ primer P1, $5 \mu \mathrm{M}$ template (left to right, T1, none, T9), 200 mM HEPES pH 7.5, and 2.5 mM 2-MeImpmG. (b) High resolution gel electrophoresis analysis of primer extension reaction with 2-MeImpmC. Primer-extension reactions contained 1 $\mu \mathrm{M}$ P1, $5 \mu \mathrm{M}$ template (left to right, T3, none, T1), $200 \mathrm{mM}$ HEPES $\mathrm{pH} 7.5$, and $2.5 \mathrm{mM}$ 2MeImpmC. 
a)

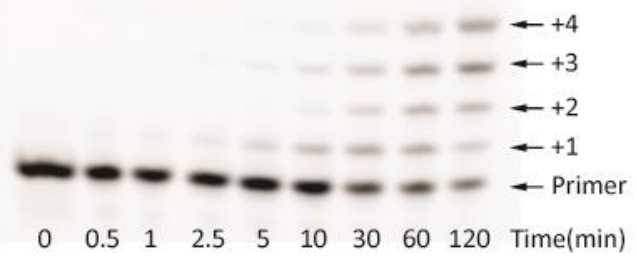

c)

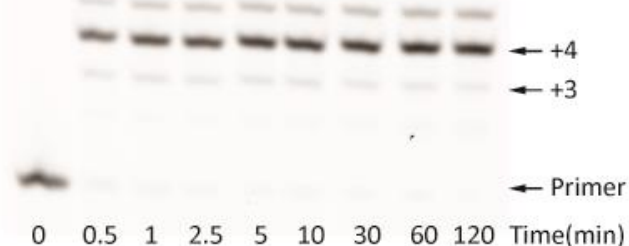

b)

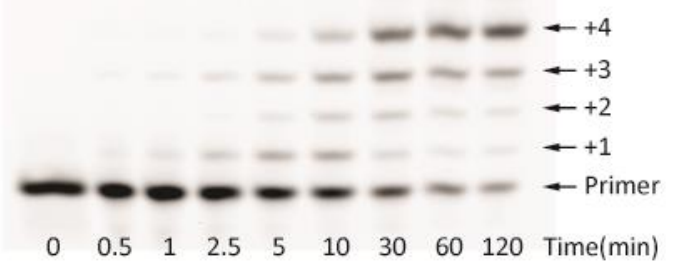

d)

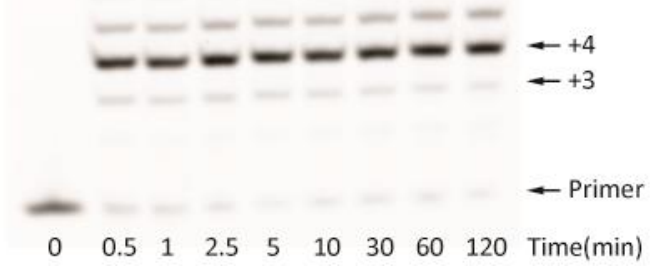

Figure S6. Comparison of template copying reactions using primers ending in 3'-amino or 3'morpholino nucleotides. (a) High resolution gel electrophoresis analysis of primer extension reactions using 3'-amino modified primer P4 (Cy3-AGUGAGUAACGC $\mathrm{NH}_{2}$ ) on a $\mathrm{G}_{4} \mathrm{RNA}$ template $\mathbf{T} 4$ in the presence of $3^{\prime}-\mathrm{NH}_{2}$-2-MeImpddC. Reaction conditions: $1 \mu \mathrm{M} \mathbf{P 4}, 5 \mu \mathrm{M} \mathbf{T 4}$, $300 \mathrm{mM}$ HEPES pH 7.5, and 5 mM 3'-NH2-2-MeImpddC. (b) as in (a) except in the presence of $100 \mathrm{mM}$ HEI. (c) High resolution gel electrophoresis analysis of primer extension reactions using 3'-morpholino modified primer P3 (Cy3-AGUGAGUAACGmC) on a $\mathrm{G}_{4}$ RNA template T4 in the presence of 2-MeImpmC. Reaction conditions: $1 \mu \mathrm{M}$ P3, $5 \mu \mathrm{M}$ T4, $300 \mathrm{mM}$ HEPES $\mathrm{pH} 7.5$, and $5 \mathrm{mM}$ 2-MeImpmC. (d) as in (c) except in the presence of $100 \mathrm{mM}$ HEI. 
a)

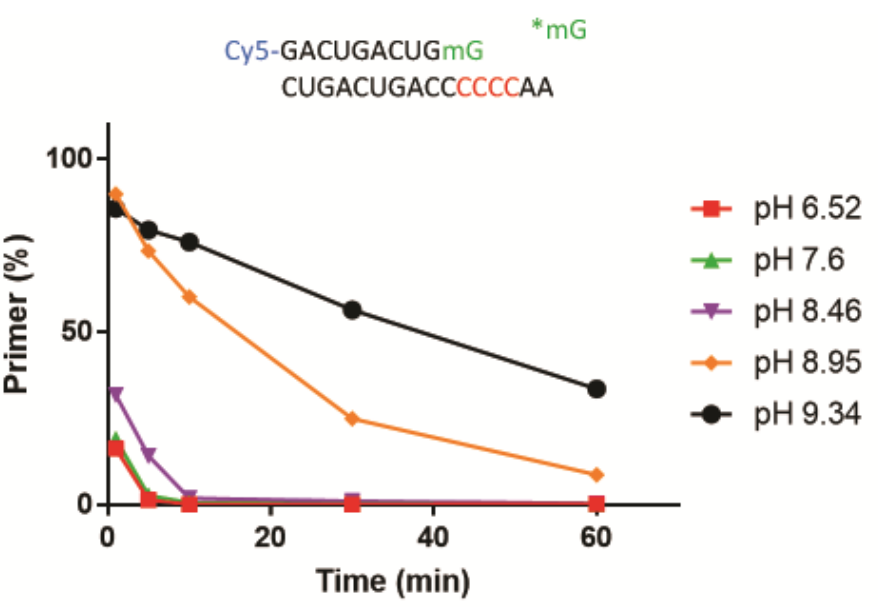

b)
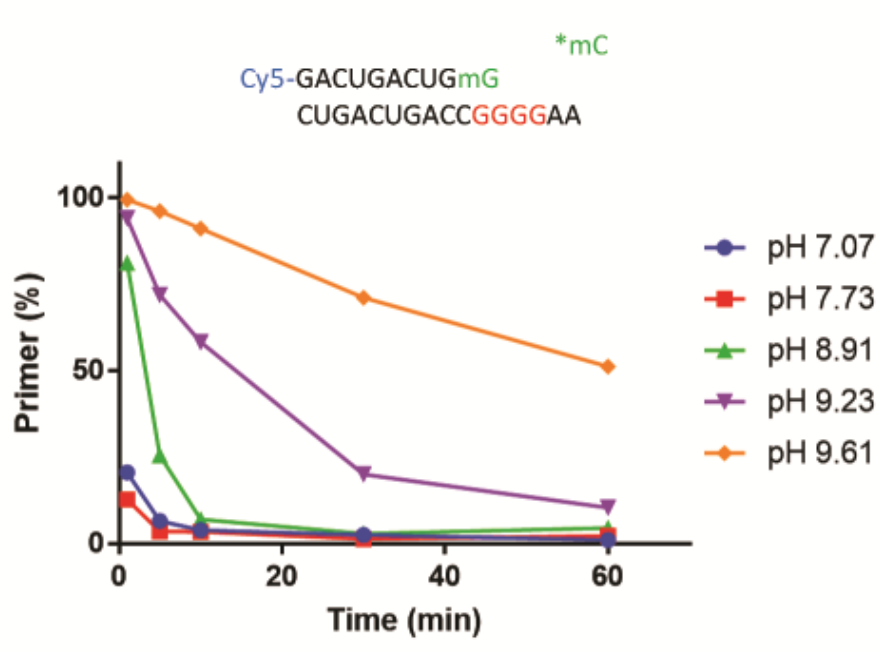

Figure S7. pH dependence of template-dependent primer extension with activated morpholinonucleotides. (a) Percentage of primer remaining vs time for the RNA $\mathrm{C}_{4}$ template copying reactions with 2-MeImpmG $(* \mathrm{mG})$ at various $\mathrm{pH}$ values. Primer-extension reactions contained 1 $\mu \mathrm{M}$ P1, $5 \mu \mathrm{M}$ T1, $200 \mathrm{mM}$ buffer, and $2.5 \mathrm{mM}$ 2-MeImpmG. (b) Percentage of primer remaining vs time for the $\mathrm{RNA} \mathrm{G}_{4}$ template copying reactions with 2-MeImpmC $(* \mathrm{mC})$ at various $\mathrm{pH}$ values. Primer-extension reactions contained $1 \mu \mathrm{M}$ P1, $5 \mu \mathrm{M}$ T3, $200 \mathrm{mM}$ buffer, and $2.5 \mathrm{mM} 2$ MeImpmC. 
a)
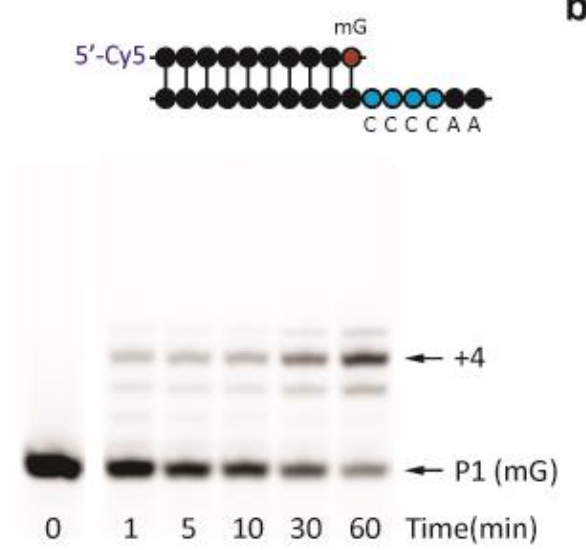

b)
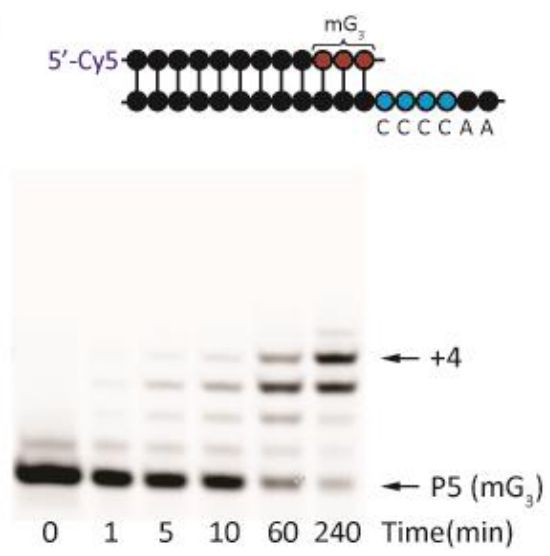

Figure S8. Comparison of primer extension reactions using primers with one vs. three terminal morpholino nucleotides. (a) Top: schematic representation of primer P1, with a single 3'morpholino-nucleotide, (Cy5-GACUGACUGmG) annealed to a $\mathrm{C}_{4}$ RNA template (T1, AACCCCCCAGUCAGUC). Bottom: high resolution PAGE analysis of the corresponding primer extension reaction with 2-MeImpmG, at high $\mathrm{pH}$ to decrease the rate of the reaction. The primer extension reaction contained $1 \mu \mathrm{M} \mathrm{P1}, 5 \mu \mathrm{M}$ T1, $150 \mathrm{mM}$ CHES pH 9.5, and $5 \mathrm{mM} 2-$ MeImpmG. (b) Top: schematic representation of prime P5, with three 3'-terminal morpholinonucleotides (Cy5-GACUGACUGmGmGmG) annealed to a $\mathrm{C}_{4}$ RNA template (T10, AACCCCCCCCAGUCAGUC). Bottom: high resolution PAGE analysis of the corresponding primer extension reaction with 2-MeImpmG. Primer-extension reactions contained $1 \mu \mathrm{M}$ P5, 5 $\mu \mathrm{M}$ T10, $150 \mathrm{mM}$ CHES pH 9.5, and 5 mM 2-MeImpmG. 
a)

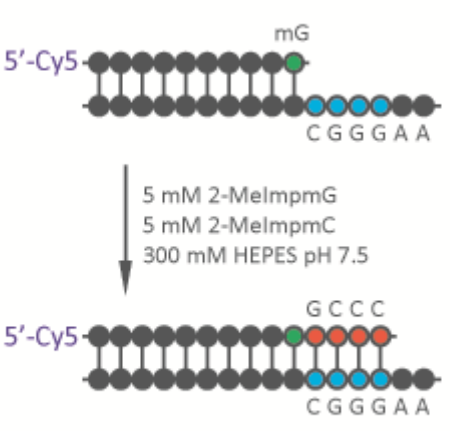

c)

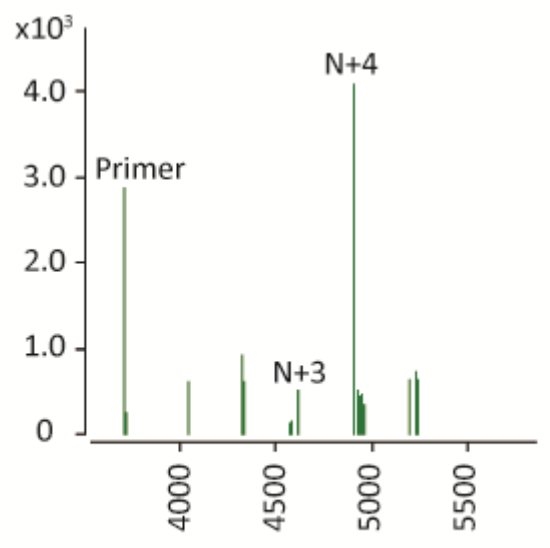

Counts vs. $\mathrm{m} / \mathrm{z}$ b)

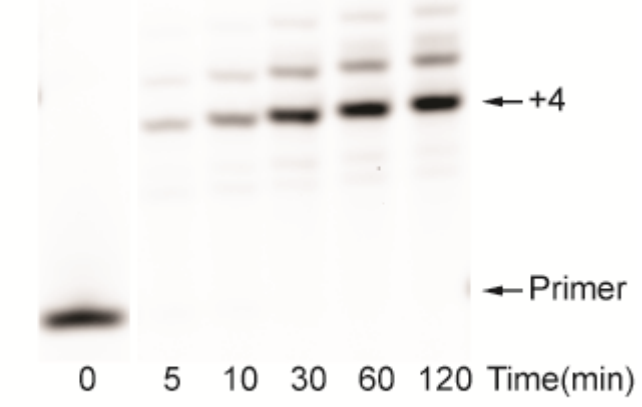

d)

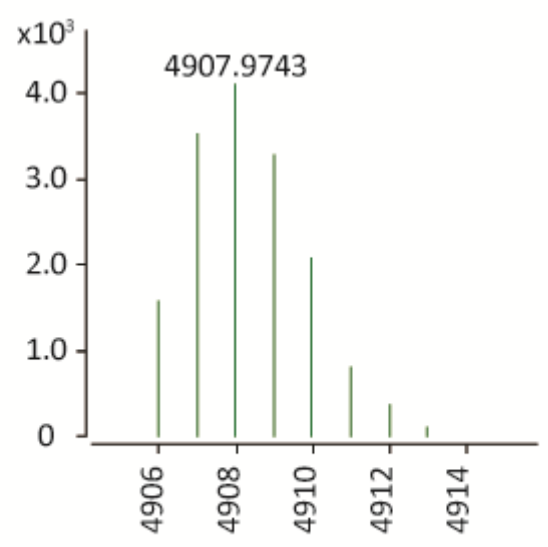

Counts vs. $\mathrm{m} / \mathrm{z}$

Figure S9. Nonenzymatic primer-extension reactions on a mixed sequence RNA template. (a) Schematic representation of primer P1 annealed to template T6, template region 3'-CGGG-5', in presence of activated MoNA monomers. 2-MeImpmG and 2-MeImpmC participate in the primer extension reaction on the mixed sequence templating region resulting in chimeric RNA/MoNA products. (b) High-resolution PAGE analysis of the primer-extension products vs. reaction time. Reaction conditions: $1 \mu \mathrm{M}$ primer P1, $5 \mu \mathrm{M}$ template T6, $300 \mathrm{mM}$ HEPES pH 7.5, $5 \mathrm{mM}$ 2MeImpmG, 5 mM 2-MeImpmC. (c) High-resolution MS analysis of the primer-extension products after 1 day. Reaction conditions: $2.75 \mu \mathrm{M}$ primer P1, $10 \mu \mathrm{M}$ template T6, $200 \mathrm{mM}$ HEPES pH 7.5, 3 mM 2-MeImpmG, 3 mM 2-MeImpmC. (d) Monoisotopic mass for the fulllength primer +4 product: calculated mass, 4905.9979 Da; observed mass, 4905.9819 Da; error, $3.3 \mathrm{ppm}$. 
a)

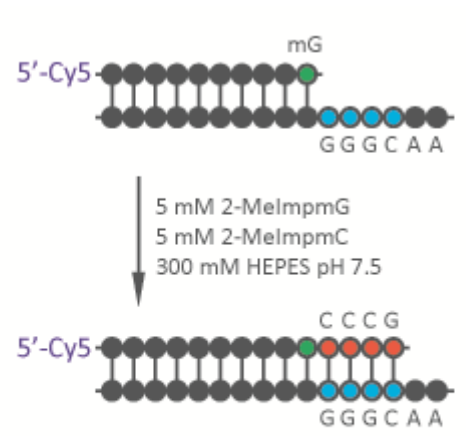

c)

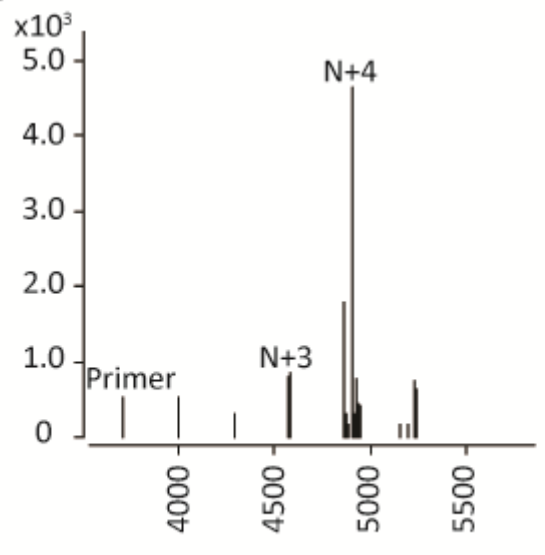

Counts vs. $\mathrm{m} / \mathrm{z}$ b)

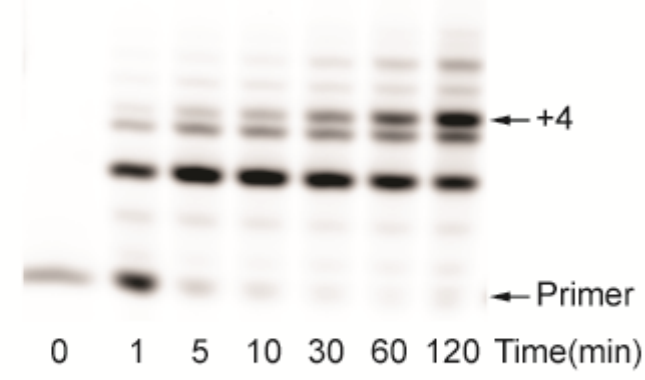

d)

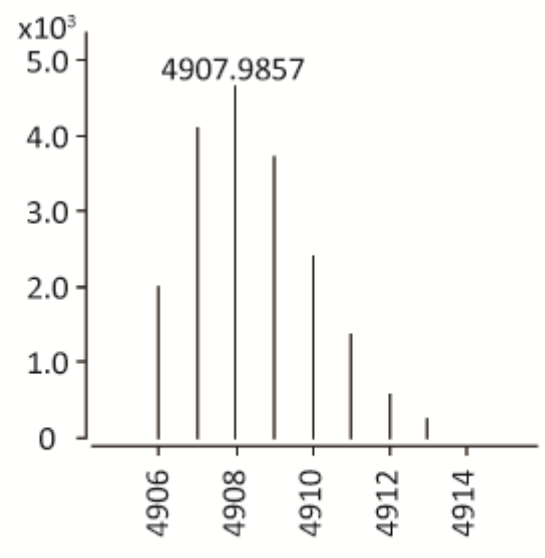

Counts vs. $\mathrm{m} / \mathrm{z}$

Figure S10. Nonenzymatic primer-extension reaction on mix sequenced RNA template. (a) Schematic representation of primer P1 annealed to a template T7, template region 3'-GGGC-5', in the presence of activated MoNA monomers. 2-MeImpmG and 2-MeImpmC participate in the primer extension reaction on the mixed sequence templating region resulting in chimeric RNA/MoNA oligomers. (b) High-resolution PAGE analysis of the primer-extension products vs. time. Reaction conditions: $1 \mu \mathrm{M}$ primer P1, $5 \mu \mathrm{M}$ template T7, $300 \mathrm{mM}$ HEPES pH 7.5, $5 \mathrm{mM}$ 2-MeImpmG, $5 \mathrm{mM}$ 2-MeImpmC. (c) High-resolution MS analysis of the primer extension products after 1 day. Reaction condition: $2.75 \mu \mathrm{M}$ primer P1, $10 \mu \mathrm{M}$ template T7, $200 \mathrm{mM}$ HEPES pH 7.5, 3 mM 2-MeImpmG, 3 mM 2-MeImpmC. (d) Monoisotopic mass for the fulllength primer +4 product: calculated mass, 4905.9979 Da; observed mass, 4905.9858 Da; error, $2.5 \mathrm{ppm}$. 
a)

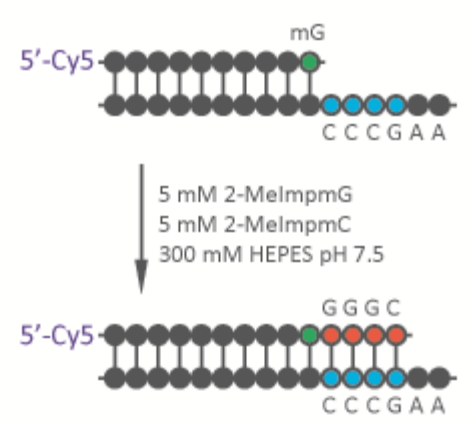

c)

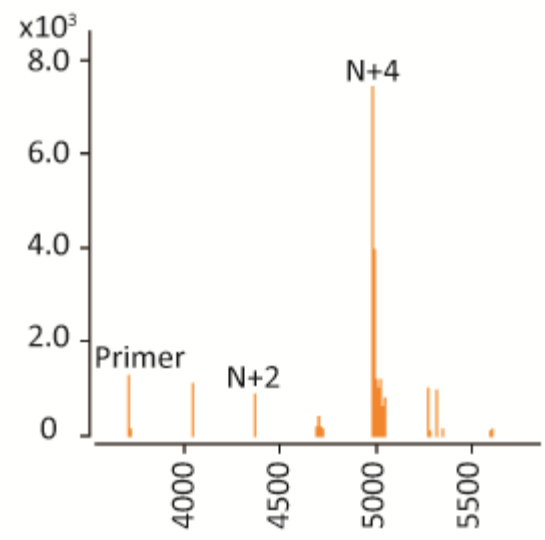

Counts vs. $\mathrm{m} / \mathrm{z}$ b)

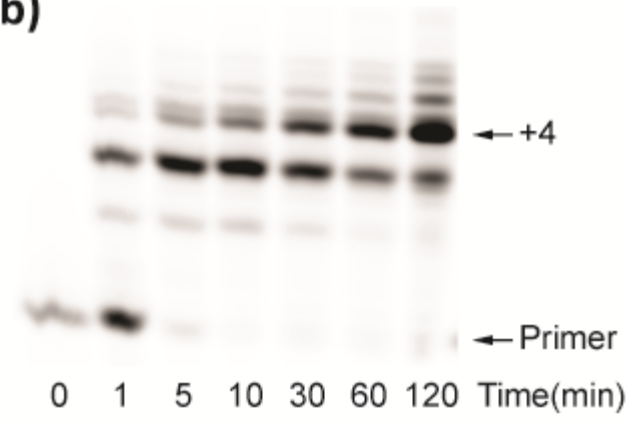

d)

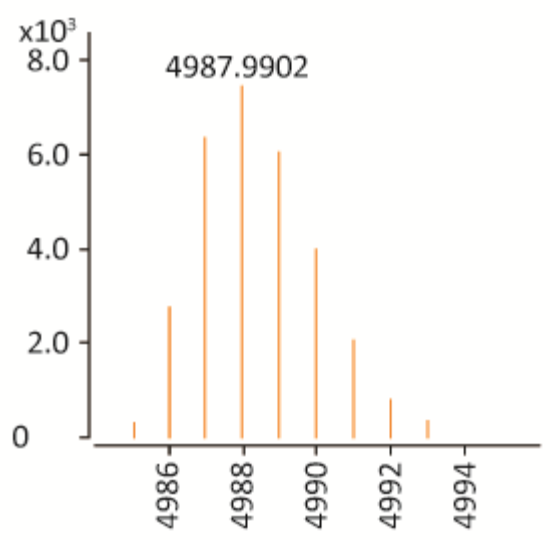

Counts vs. $\mathrm{m} / \mathrm{z}$

Figure S11. Nonenzymatic primer-extension reactions on a mixed sequenced RNA template. (a) Schematic representation of primer $\mathbf{P 1}$ annealed to template $\mathbf{T 8}$, template region $3^{\prime}-\mathrm{CCCG}-5^{\prime}$, in the presence of activated MoNA monomers. 2-MeImpmG and 2-MeImpmC participate in the primer extension reaction on the mixed sequence template resulting in chimeric RNA/MoNA products. (b) High-resolution PAGE analysis of the primer extension products vs. time. Reaction conditions: $1 \mu \mathrm{M}$ primer P1, $5 \mu \mathrm{M}$ template T8, $300 \mathrm{mM}$ HEPES pH 7.5, $5 \mathrm{mM}$ 2-MeImpmG, 5 mM 2-MeImpmC. (c) High-resolution MS analysis of the primer extension products after 1 day. Reaction conditions: $2.75 \mu \mathrm{M}$ primer P1, $10 \mu \mathrm{M}$ template T8, $200 \mathrm{mM}$ HEPES pH 7.5, 3 mM 2MeImpmG, 3 mM 2-MeImpmC. (d) Monoisotopic mass for the full-length primer +4 product: calculated mass, 4986.0102 Da; observed mass, 4985.9974 Da; error, 2.6 ppm. 


\section{X-ray crystallography}

Single crystals were mounted on a diffractometer and data was collected at $100 \mathrm{~K}$. The intensities of the reflections were measured with a Bruker APEX DUO CCD diffractometer ( $\mathrm{Cu}_{\mathrm{K} \alpha}$ radiation, $\lambda=1.54178 \AA$ ) equipped with an Oxford Cryosystems nitrogen flow apparatus. The collection method involved $1.0^{\circ}$ scans in $\omega$ at $-30^{\circ},-55^{\circ},-80^{\circ}, 30^{\circ}, 55^{\circ}, 80^{\circ}$ and $115^{\circ}$ in $2 \theta$. Data integration down to 0.84 A resolution was carried out using SAINT V8.37 A (Bruker diffractometer, 2015) with reflection spot size optimization. Absorption corrections were made with the program SADABS (Bruker diffractometer, 2015). The structure was solved by the Intrinsic Phasing method and refined by least-squares methods again $F^{2}$ using SHELXT-2014 ${ }^{1}$ and SHELXL-2014 ${ }^{2}$ with OLEX 2 interface ${ }^{3}$. Non-hydrogen atoms were refined anisotropically, and hydrogen atoms were allowed to ride on their respective atoms.

\section{Morpholino Guanosine}

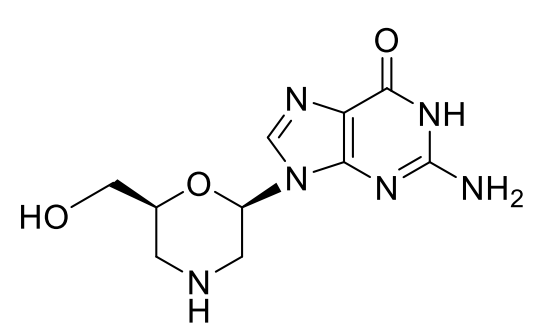

Morpholino guanosine was initially crystallized using the slow cooling method. A saturated solution of morpholino guanosine was prepared in 1:1 EtOH: $\mathrm{H}_{2} \mathrm{O}(500 \mu \mathrm{L})$ at $65^{\circ} \mathrm{C}$. The solution was transferred to a glass vial. The vial was then sealed and placed together with a beaker of water $(200 \mathrm{~mL})$ at $65^{\circ} \mathrm{C}$ inside a styrofoam container. Small needle-shaped crystals were obtained after the solution slowly cooled to $4{ }^{\circ} \mathrm{C}$. The resulting crystals were then used to seed the growth of new crystals using the vapor diffusion method. A saturated solution of morpholino guanosine in 1:1 EtOH: $\mathrm{H}_{2} \mathrm{O}(200$ $\mu \mathrm{L})$ was prepared in a small open glass container. A small amount of seed crystals obtained from slow cooling was added. The glass container was then sealed inside a $20 \mathrm{~mL}$ glass vial containing $5 \mathrm{~mL}$ of hexane. Crystals grew to the desired size at room temperature. The ORTEP plot was produced with the SHELXL-2014 program (Figure S12). Crystal data as well as details of data collection and refinement are summarized in Table S2. Cambridge Crystallographic Data Centre deposition number 1916567. 


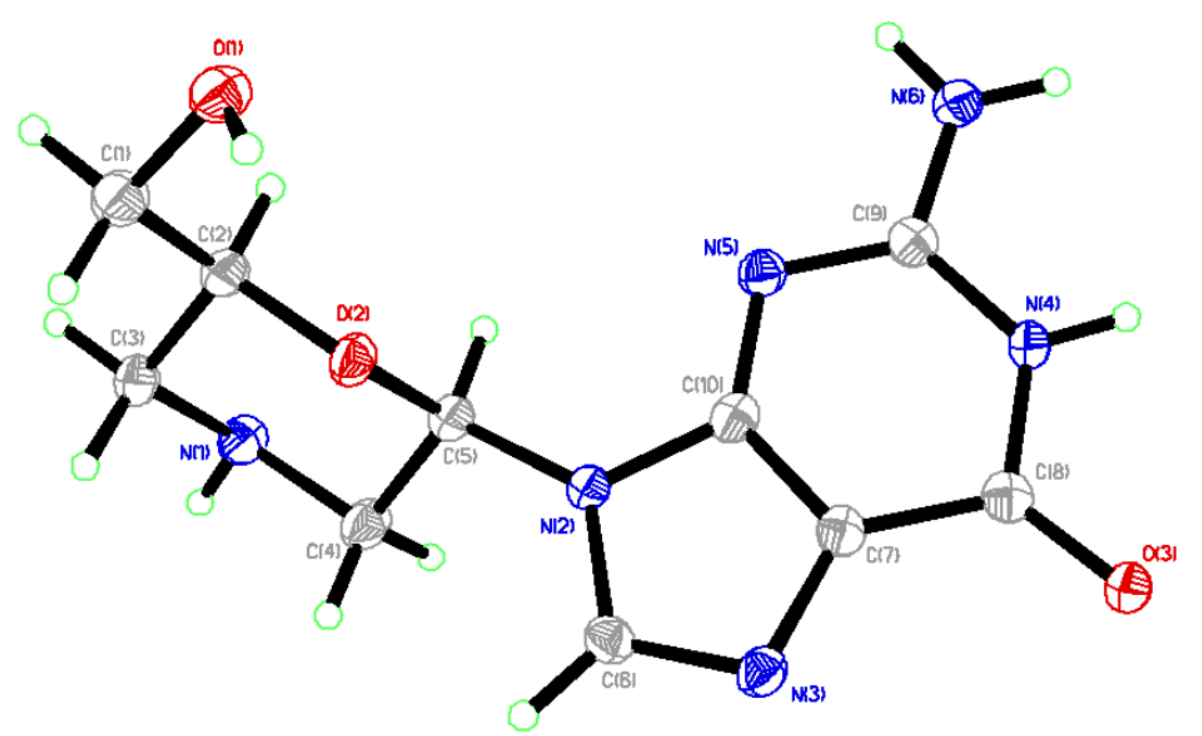

Figure S12. ORTEP plot of morpholino guanosine. Perspective views showing 50\% probability displacement

Table S2. Experimental details for morpholino guanosine crystal

\begin{tabular}{|c|c|}
\hline Crystal data & \\
\hline Chemical formula & $\mathrm{C}_{40} \mathrm{H}_{68} \mathrm{~N}_{24} \mathrm{O}_{18}$ \\
\hline$M_{\mathrm{r}}$ & 1173.18 \\
\hline Crystal system, space group & Monoclinic, $P 2_{1}$ \\
\hline Temperature (K) & 100 \\
\hline$a, b, c(\AA)$ & $8.38505(12), 36.0429(5), 8.62496(13)$ \\
\hline$\beta\left(^{\circ}\right)$ & $98.4463(12)$ \\
\hline$V\left(\AA^{3}\right)$ & $2578.38(6)$ \\
\hline$Z$ & 2 \\
\hline Radiation type & $\mathrm{Cu} K \alpha$ \\
\hline$\mu\left(\mathrm{mm}^{-1}\right)$ & 1.03 \\
\hline Crystal size $(\mathrm{mm})$ & $0.12 \times 0.08 \times 0.02$ \\
\hline Data collection & \\
\hline Diffractometer & Bruker D8 goniometer with CCD area detector \\
\hline Absorption correction & $\begin{array}{l}\text { Multi-scan } \\
S A D A B S\end{array}$ \\
\hline
\end{tabular}




\begin{tabular}{|l|l|}
\hline$T_{\min }, T_{\max }$ & $0.783,0.864$ \\
\hline $\begin{array}{l}\text { No. of measured, independent and } \\
\text { observed }[I>2 \sigma(I)] \text { reflections }\end{array}$ & $66099,8798,8331$ \\
\hline$R_{\text {int }}$ & 0.072 \\
\hline$(\sin \theta / \lambda)_{\max }\left(\AA^{-1}\right)$ & 0.595 \\
\hline & \multicolumn{2}{|l|}{} \\
\hline Refinement & $0.043,0.119,1.02$ \\
\hline$R\left[F^{2}>2 \sigma\left(F^{2}\right)\right], w R\left(F^{2}\right), S$ & 8798 \\
\hline No. of reflections & 772 \\
\hline No. of parameters & 8 \\
\hline No. of restraints & H atoms treated by a mixture of independent and constrained refinement \\
\hline H-atom treatment & $0.40,-0.32$ \\
\hline$\Delta \rho_{\text {max }}, \Delta \rho_{\min }\left(\mathrm{e} \AA^{-3}\right)$ & Flack x determined using 3721 quotients [(I+)-(I-) $] /[(\mathrm{I}+)+(\mathrm{I}-)]^{4}$ \\
\hline Absolute structure & $0.02(9)$ \\
\hline Absolute structure parameter &
\end{tabular}

\section{Morpholino Cytidine}<smiles>Nc1ccn([C@H]2CNC[C@H](CO)O2)c(=O)n1</smiles>

Morpholino cytidine was crystallized using the vapor diffusion method. A near-saturated solution of morpholino cytidine in 1:1 EtOH: $\mathrm{H}_{2} \mathrm{O}(100 \mu \mathrm{L})$ was prepared in a small open glass container. It was then sealed inside a $20 \mathrm{~mL}$ glass vial containing $5 \mathrm{~mL}$ of heptane. Crystals were obtained at room temperature. The ORTEP plot was produced with SHELXL-2014 program (Figure S13). Crystal data as well as details of data collection and refinement are summarized in Table S3. Cambridge Crystallographic Data Centre deposition number 1916568. 


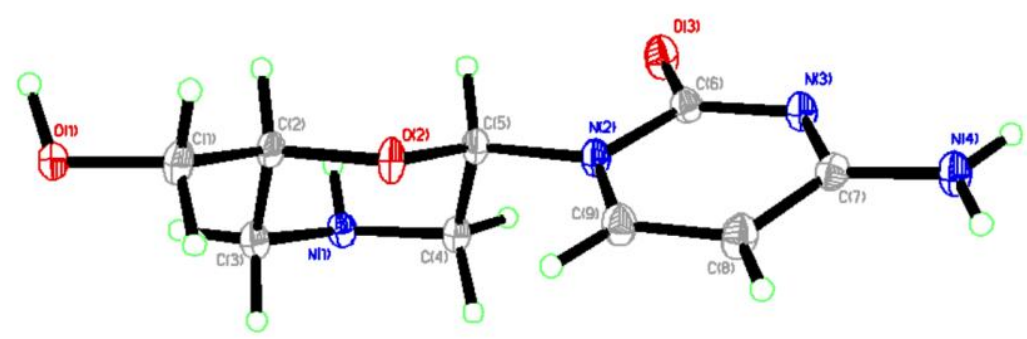

Figure S13. The ORTEP plot of morpholino cytidine. Perspective views showing 50\% probability displacement

\section{Table S3. Experimental details for morpholino cytidine crystal}

\begin{tabular}{|c|c|}
\hline Crystal data & \\
\hline Chemical formula & $\mathrm{C}_{9} \mathrm{H}_{16} \mathrm{~N}_{4} \mathrm{O}_{4}$ \\
\hline$M_{\mathrm{r}}$ & 244.26 \\
\hline Crystal system, space group & Orthorhombic, $P 2_{1} 2_{1} 2_{1}$ \\
\hline Temperature (K) & 100 \\
\hline$a, b, c(\AA)$ & $8.3359(4), 11.5375(5), 11.8279(5)$ \\
\hline$V\left(\AA^{3}\right)$ & $1137.55(9)$ \\
\hline$Z$ & 4 \\
\hline Radiation type & $\mathrm{Cu} K \alpha$ \\
\hline$\mu\left(\mathrm{mm}^{-1}\right)$ & 0.96 \\
\hline Crystal size $(\mathrm{mm})$ & $0.18 \times 0.16 \times 0.14$ \\
\hline Data collection & \\
\hline Diffractometer & Bruker D8 goniometer with CCD area detector \\
\hline Absorption correction & $\begin{array}{l}\text { Multi-scan } \\
S A D A B S\end{array}$ \\
\hline$T_{\min }, T_{\max }$ & $0.747,0.806$ \\
\hline $\begin{array}{l}\text { No. of measured, independent and } \\
\text { observed }[I>2 \sigma(I)] \text { reflections }\end{array}$ & $23324,1995,1988$ \\
\hline$R_{\text {int }}$ & 0.031 \\
\hline$(\sin \theta / \lambda)_{\max }\left(\AA^{-1}\right)$ & 0.596 \\
\hline
\end{tabular}




\begin{tabular}{|l|l|}
\hline \multicolumn{2}{|l|}{ Refinement } \\
\hline$R\left[F^{2}>2 \sigma\left(F^{2}\right)\right], w R\left(F^{2}\right), S$ & $0.023,0.061,1.07$ \\
\hline No. of reflections & 1995 \\
\hline No. of parameters & 179 \\
\hline $\mathrm{H}$-atom treatment & $\mathrm{H}$ atoms treated by a mixture of independent and constrained refinement \\
\hline$\Delta \rho_{\text {max }}, \Delta \rho_{\text {min }}\left(\mathrm{e} \AA^{-3}\right)$ & $0.19,-0.17$ \\
\hline Absolute structure & Flack x determined using 814 quotients $[(\mathrm{I}+)-(\mathrm{I}-)] /[(\mathrm{I}+)+(\mathrm{I}-)]^{4}$ \\
\hline Absolute structure parameter & $-0.03(4)$ \\
\hline
\end{tabular}




\section{NMR Spectra}

${ }^{1} \mathrm{H}$ spectrum of 5'-O-DMTr-morpholino guanosine

solvent: CD3OD
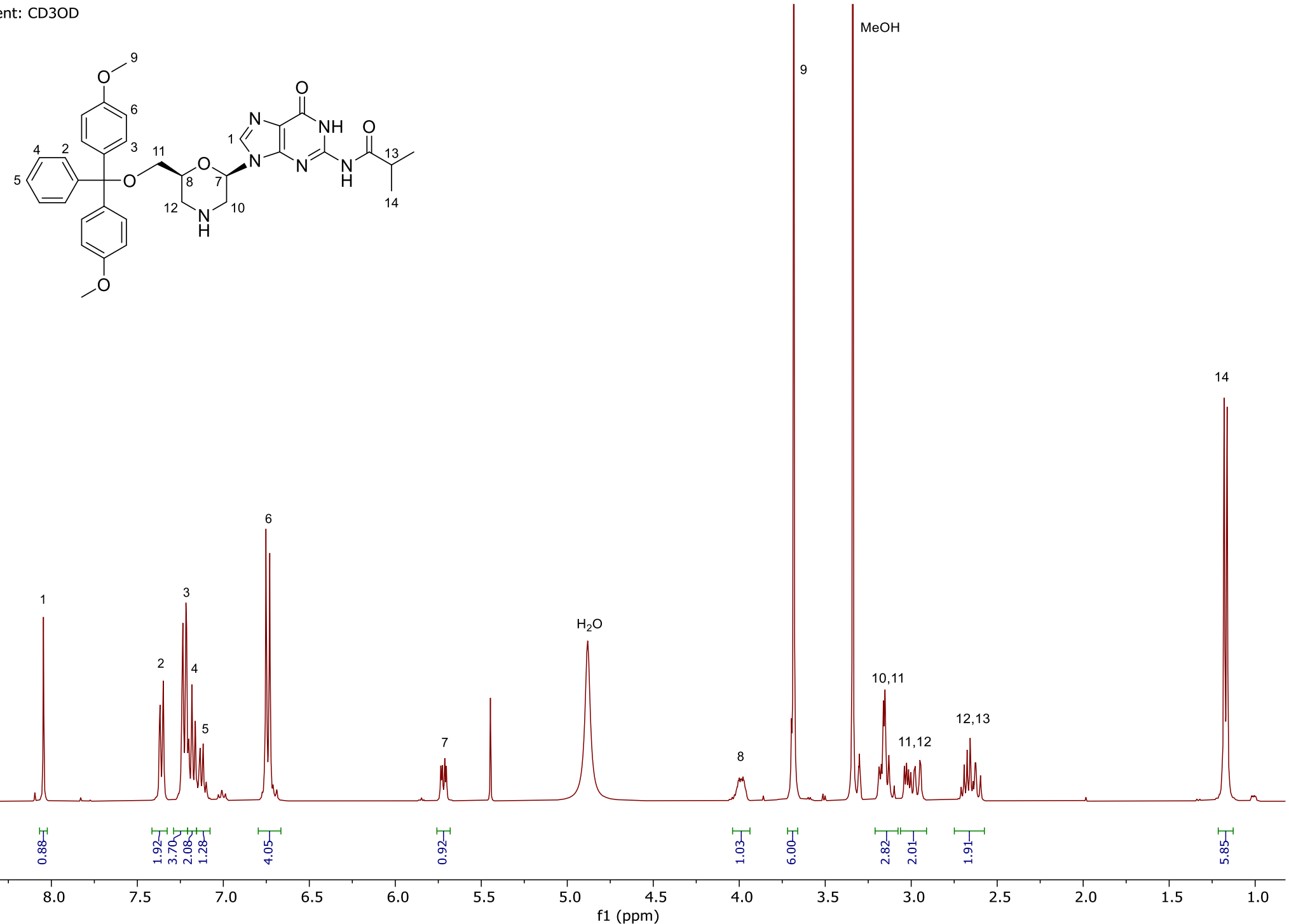
${ }^{13} \mathrm{C}$ spectrum of 5'-O-DMTr-morpholino guanosine

solvent: CD3OD
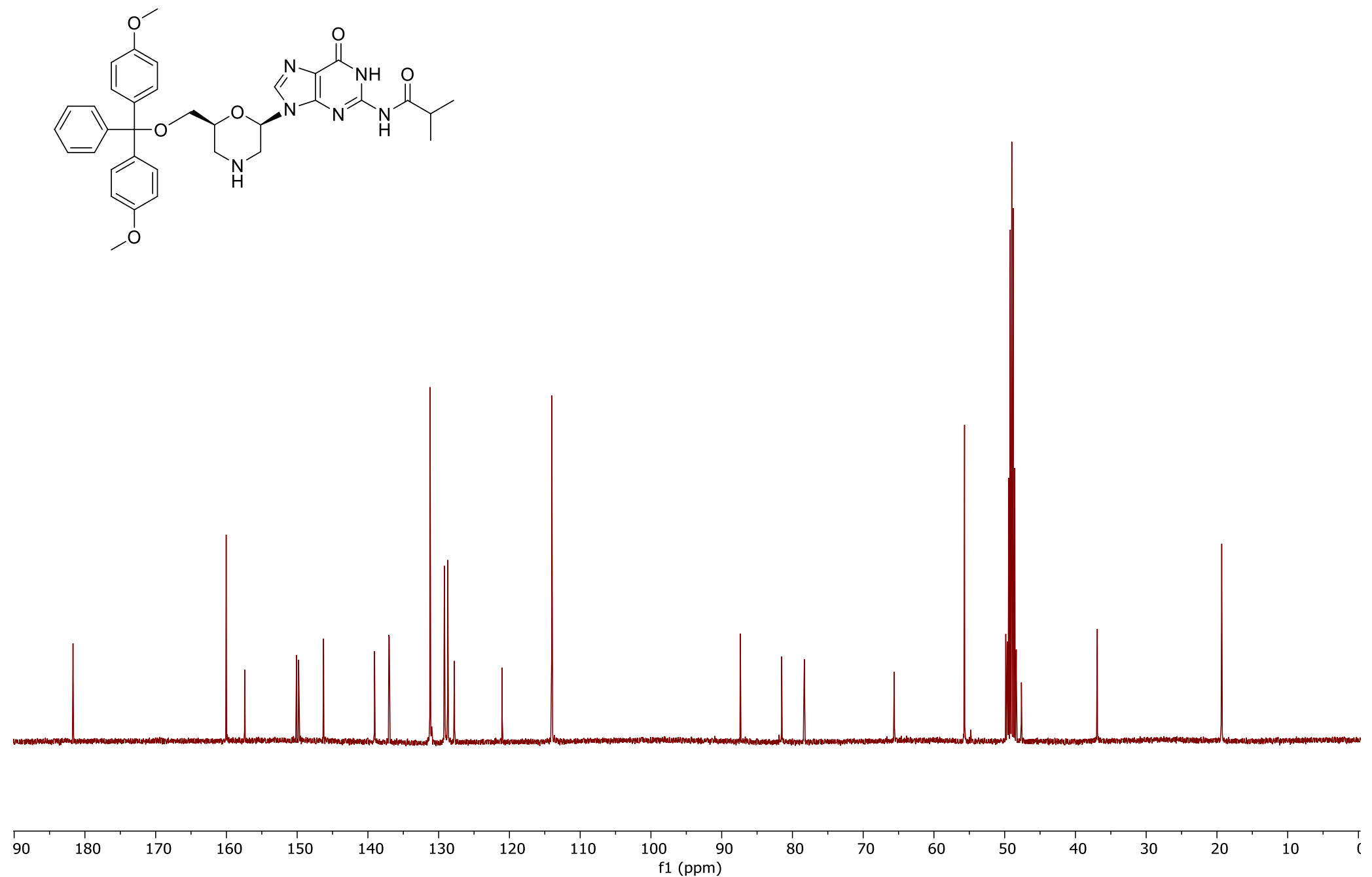


\section{${ }^{1} \mathrm{H}$ spectrum of 5'-O-DMTr-morpholino cytidine}

solvent: CD3OD
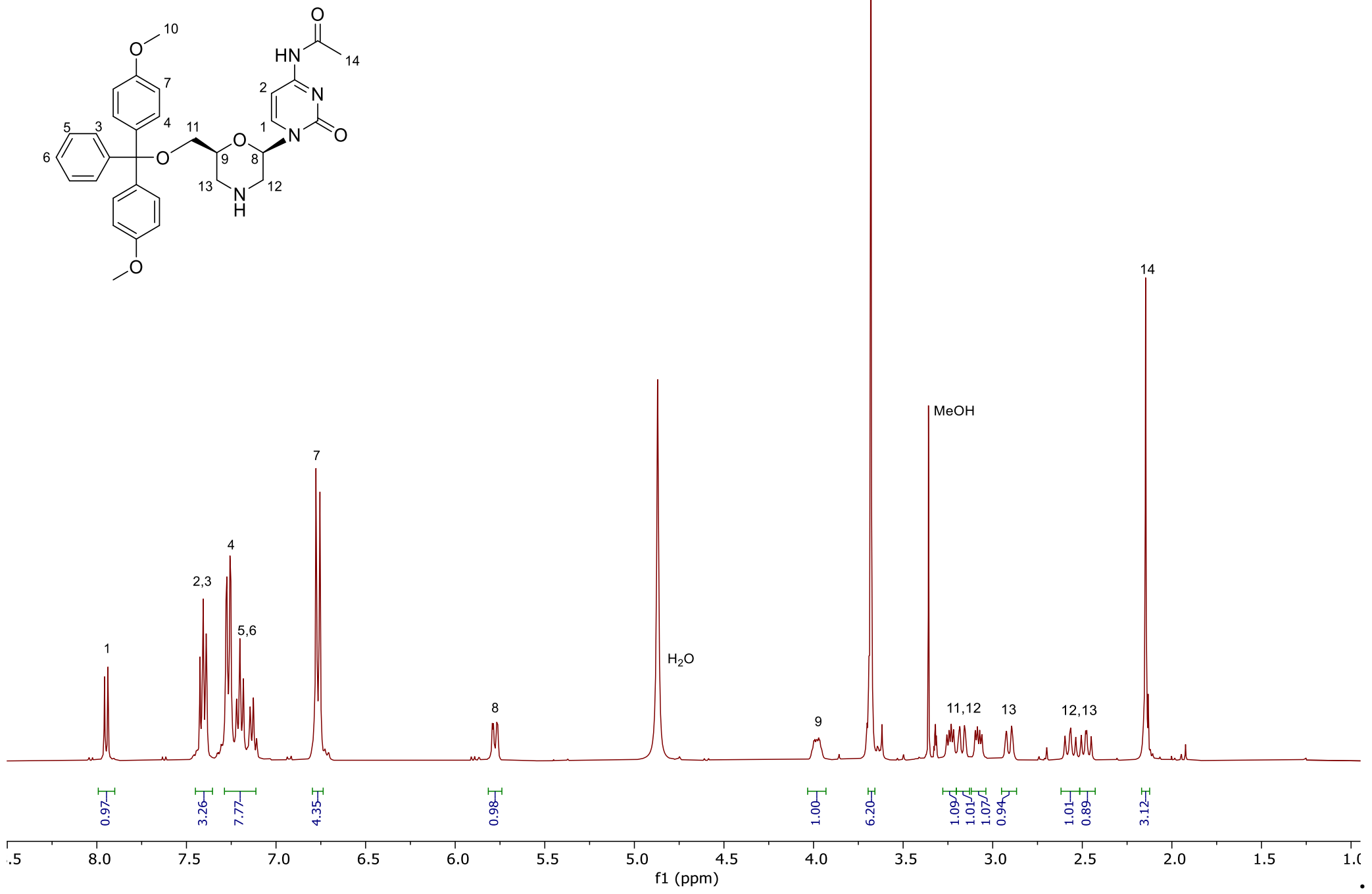
${ }^{13} \mathrm{C}$ spectrum of 5'-O-DMTr-morpholino cytidine

solvent: CD3OD
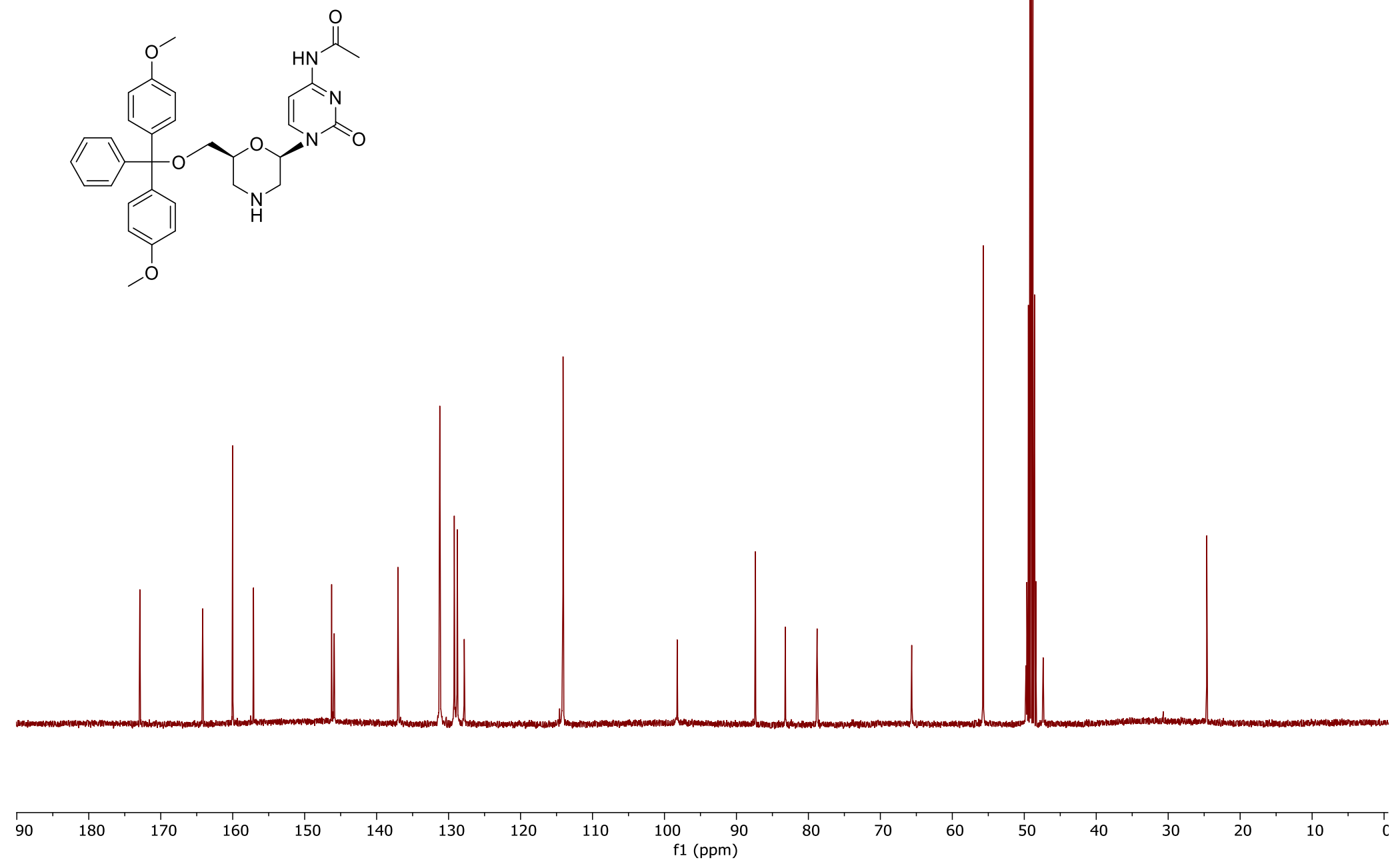
${ }^{1} \mathrm{H}$ spectrum of morpholino guanosine

solvent: D2O
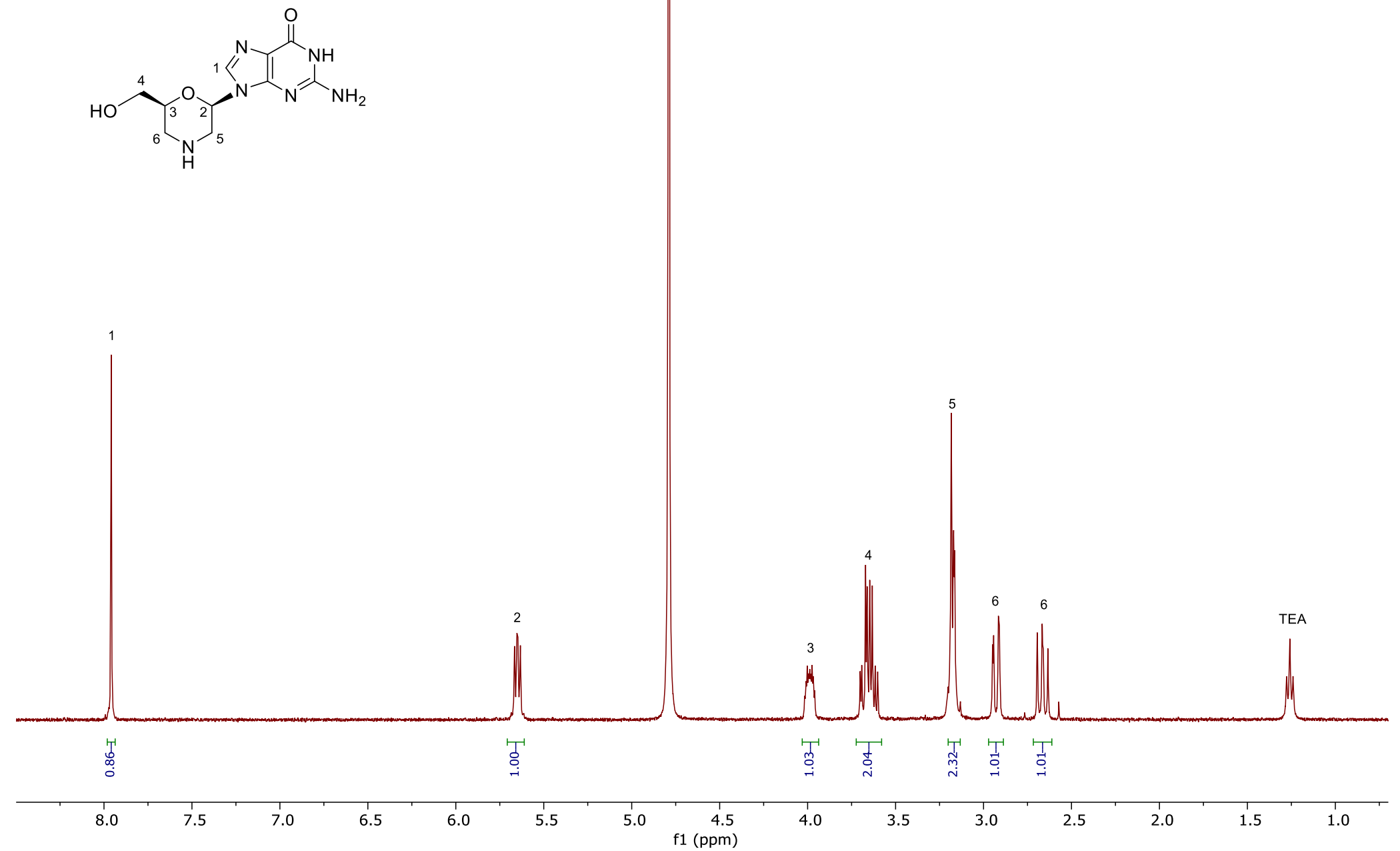
${ }^{1} \mathrm{H}$ spectrum of morpholino cytidine

solvent: D2O

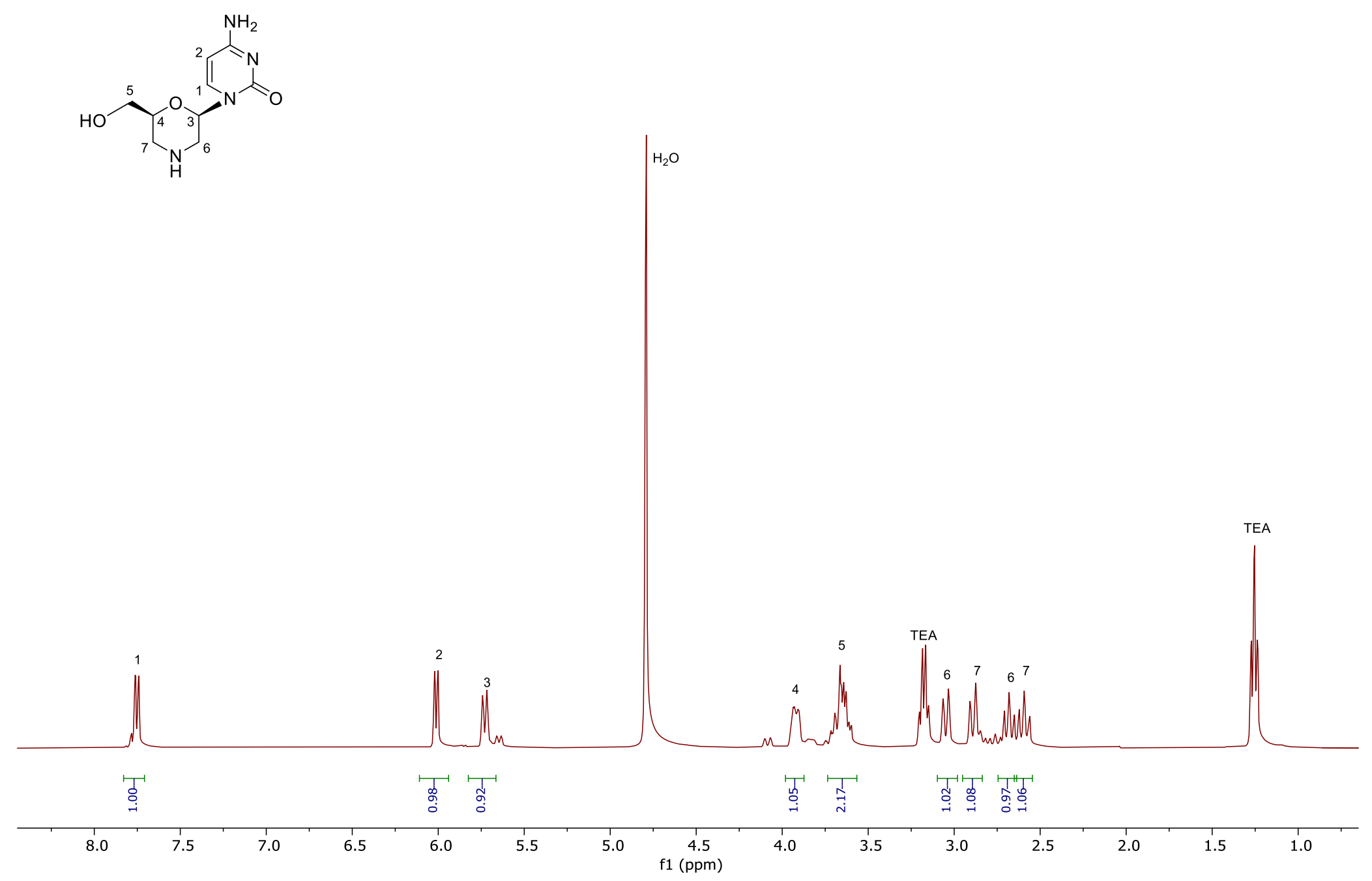




\section{References}

1. Sheldrick, G., SHELXT - Integrated space-group and crystal-structure determination. Acta Crystallographica Section A 2015, 71 (1), 3-8.

2. Sheldrick, G., Crystal structure refinement with SHELXL. Acta Crystallographica Section C 2015, 71 (1), 3-8.

3. Dolomanov, O. V.; Bourhis, L. J.; Gildea, R. J.; Howard, J. A. K.; Puschmann, H., OLEX2: a complete structure solution, refinement and analysis program. Journal of Applied Crystallography 2009, 42 (2), 339-341.

4. Parsons, S.; Flack, H. D.; Wagner, T., Use of intensity quotients and differences in absolute structure refinement. Acta Crystallographica Section B 2013, 69 (3), 249-259. 